\title{
Application of advanced synchrotron radiation-based Fourier transform infrared (SR-FTIR) microspectroscopy to animal nutrition and feed science: a novel approach
}

\author{
P. $\mathrm{Yu}^{*}$ \\ Department of Animal and Poultry Science, College of Agriculture, University of Saskatchewan, 6D34 Agriculture Building \\ 51 Campus Drive, Saskatoon, S7N 5A8, Canada
}

(Received 6 April 2004 - Revised 23 June 2004 - Accepted 29 June 2004)

\begin{abstract}
Synchrotron radiation-based Fourier transform IR (SR-FTIR) microspectroscopy has been developed as a rapid, direct, non-destructive and bioanalytical technique. This technique, taking advantage of synchrotron light brightness and a small effective source size, is capable of exploring the molecular chemistry within the microstructures of a biological tissue without the destruction of inherent structures at ultraspatial resolutions within cellular dimensions. This is in contrast to traditional 'wet' chemical methods, which, during processing for analysis, often result in the destruction of the intrinsic structures of feeds. To date there has been very little application of this technique to the study of feed materials in relation to animal nutrient utilisation. The present article reviews four applications of the SR-FTIR bioanalytical technique as a novel approach in animal nutrition and feed science research. Application 1 showed that using the SR-FTIR technique, intensities and the distribution of the biological components (such as lignin, protein, lipid, structural and non-structural carbohydrates and their ratios) in the microstructure of plant tissue within cellular dimensions could be imaged. The implication from this study is that we can chemically define the intrinsic feed structure and compare feed tissues according to spectroscopic characteristics, functional groups, spatial distribution and chemical intensity. Application 2 showed that the ultrastructural-chemical makeup and density of yellowand brown-seeded Brassica rape could be explored. This structural-chemical information could be used for the prediction of rapeseed quality and nutritive value for man and animals and for rapeseed breeding programmes for selecting superior varieties for special purposes. More research is required to define the extent of differences that exist between the yellow- and brown-seeded Brassica rape. Application 3 showed with the SR-FTIR technique that chemical differences in the ultrastructural matrix of endosperm tissue between Harrington (malting-type) and Valier (feed-type) barley in relation to rumen degradation characteristics could be identified. The results indicated that the greater association of the protein matrix with the starch granules in the endosperm tissue of Valier barley may limit the access of ruminal micro-organisms to the starch granules and thus reduce the rate and extent of rumen degradation relative to that of Harrington barley. It is the first time that the microstructural matrix in the endosperm of barley has been revealed by using the SR-FTIR technique, which makes it possible to link feed intrinsic structures to nutrient utilisation and digestive behaviour in ruminants. Application 4 showed with the SRFTIR technique that the chemical features of various feed protein (amide I) secondary structures (such as feather, wheat, oats and barley) could be quantified. With a multi-component fitting program (Lorentz function), the results showed feather containing about $88 \% \beta$-sheet and $4 \% \alpha$-helix, barley containing about $17 \% \beta$-sheet and $71 \% \alpha$-helix; oats containing about $2 \% \beta$-sheet and $92 \% \alpha$-helix; and wheat containing about $42 \% \beta$-sheet and $50 \% \alpha$-helix. The relative percentage of the two may influence protein value. A high percentage of $\beta$-sheet may reduce the access of gastrointestinal digestive enzymes to the protein structure. Further study is required on feed protein secondary structures in relation to enzyme accessibility and digestibility. In conclusion, the SR-FTIR technique can be used for feed science and animal nutrition research. However, the main disadvantage of this technique is the requirement for a special light source; a synchrotron beam.
\end{abstract}

Synchrotron: Infrared microspectroscopy: Chemical imaging and mapping: Feed chemistry: Animal nutrition

Traditional 'wet' analytical chemistry usually looks for a specific known component through homogenisation of the tissue and separation of the components of interest from the complex matrix. As a result, the information about the spatial origin and distribution of the component of interest is lost and the object of the analysis is destroyed

\footnotetext{
Abbreviations: CHO, carbohydrate; FTIR, Fourier transform infrared; NIR, near infrared; NSLS-BNL, National Synchrotron Light Source in Brookhaven National Laboratory; SRC, Synchrotron Radiation Center; SR-FTIR, synchrotron radiation-based Fourier transform infrared.

* Corresponding author: Dr P. Yu, fax + 1306966 4151, email yupe@sask.usask.ca
} 
(Budevska, 2002). Traditional 'wet' chemical analyses rely heavily on the use of harsh chemicals and derivatisation, therefore altering the native feed structures and possibly generating artifacts. The analyses also require reasonable amounts of feed material ( $\mathrm{g}$ or mg levels), which usually means that they are carried out on composite samples of tissues (Stewart et al. 1995). Also, traditional 'wet' chemical analysis is time consuming, expensive and prone to errors within and between laboratories.

\section{Near infrared, Raman and Fourier transform infrared spectroscopic techniques for feed assessment}

In feed analysis and quality assessment, spectroscopic techniques including near IR (NIR), Raman and globar-sourced Fourier transform IR (FTIR) spectroscopy exist. The NIR technique is commonly used. The NIR method is a computerised optical technique, in which absorption of near IR radiation is measured on a set of ground samples and a mathematical relationship is established between the optical data and chemical composition obtained by other methods. The NIR technique has been applied in a variety of fields including ruminant nutrition (Marten, 1989). The first use of the NIR method for the analysis of forage quality was reported by Norris \& Barness (1976). Since then, considerable research has been directed towards using the NIR technique to predict the composition of feedstuffs and faeces, in vivo digestibility, intake etc. The advantages of the NIR method, described by Norris (1989), are speed in analysis, simplicity of operation, and the multiplicity of NIR analyses that can be performed on a given sample. The fatal disadvantages are dependent on an appropriate calibration to the direct measurement of the variable for which the NIR method predicts a value, the lack of adequate theory to support the measurement (Norris, 1988), and measuring a set of ground samples. The measuring of ground samples means that the feed sample's inherent structures are destroyed and that the spatial origin and distribution of the components of interest are lost. The other two IR spectroscopic techniques (Raman and FTIR spectroscopy) are not common in the feed industry. FTIR spectroscopy has limited flexibility for the analysis of solids. Raman spectroscopy instruments suitable for routine use are only recently becoming available and their practical utility requires study. Again, the fatal disadvantage of the two techniques is that the sample needs to be ground. Therefore NIR, Raman and FTIR spectroscopy are not able to link a feed's inherent structural information to digestive behaviour and nutrient utilisation or reveal chemical features at cellular and subcellular levels.

\section{Synchrotron-based bioanalytical technique}

When a globar-sourced FTIR spectroscopy is combined with a microscope, the technique is called 'FTIR microspectroscopy'. This technique is able to identify molecular constituents in biological samples from their vibrational spectra in the mid-IR region (Marinkovic et al. 2002). A drawback of FTIR microspectroscopy is resulting diffraction effects if the aperture is decreased to limit the field of view to a small region of interest. At the same time, less light overall reaches the detectors, and hence the signal:noise ratio decreases (Wetzel et al. 1998; Miller et al. 2000; Raab \& Martin, 2001; Wetzel, 2001; Bonetta et al. 2002; Miller, 2002). In order to study the structuralchemical features of plant feeds, spectral data at the diffraction limit or a few microns in each spatial dimension are collected; synchrotrons and free electron lasers can achieve this. In contrast, the brightness of conventional bench-top IR sources is simply too low by two to three orders of magnitude (Raab \& Martin, 2001; Bonetta et al. 2002).

A synchrotron is a giant particle accelerator that turns electrons into light (Synchrotron facts, 2004). Synchrotron light is extremely bright (millions of times brighter than sunlight). The beam is non-divergent, intense and extremely fine (Wetzel et al. 1998; Miller et al. 2000; Raab \& Martin, 2001; Miller, 2002).

When a synchrotron light (IR) source, FTIR spectroscopy and microscopy are combined together, the technique is called 'synchrotron radiation-based FTIR (SR-FTIR) microspectroscopy'. Recently, the SR-FTIR method has been developed as a rapid, direct, non-destructive and non-invasive bioanalytical technique. This technique, taking advantages of synchrotron light brightness (which is usually 100-1000 times brighter than a conventional globar source and has a small effective source size), is capable of exploring the molecular chemistry within microstructures of biological samples with a high signal: noise ratio at ultraspatial resolutions as fine as $3-10 \mu \mathrm{m}$ (Miller et al. 1998, 2000; Wetzel et al. 1998; Raab \& Martin, 2001; Wetzel, 2001; Bonetta et al. 2002; Marinkovic et al. 2002; Miller, 2002; Vogel et al. 2002; Yu et al. $2003 b, c, 2004 c)$. This technique is able to provide information relating to the quantity, composition, structure and distribution of chemical constituents and functional groups in a tissue and can encompass a wider spectral range so that more detailed structural information can be extracted. The technique can be used to increase the fundamental understanding of feed structures at the cellular level and bring a new level of understanding of analytical information (Budevska, 2002; Yu et al. 2003b,c, 2004c).

\section{Objective and applications}

To date there has been very little application of this synchrotron-based analytical technique (SR-FTIR) to the study of the structural-chemical features (bonding and functional group characteristics) of feed materials. These structural-chemical features are associated with feed quality and nutritive value in animal diets. The objective of the present article was to review four applications of the synchrotron-based bioanalytical technique (SR-FTIR) for feed science and animal nutrition research. In application 1, using SR-FTIR microspectroscopy, the intensities and distribution of biological components (such as lignin, protein, lipid, structural and non-structural carbohydrates $(\mathrm{CHO})$ ) and their ratios in the microstructure of barley tissue within the cellular dimension could be imaged. In application 2, the ultrastructural-chemical makeup and density of yellow- and brown-seeded Brassica rape could be explored and compared. This structural-chemical 
information could be used for the prediction of rapeseed quality and nutritive value for man and animals. In application 3, chemical differences in the ultrastructural matrix of endosperm tissue between Harrington (maltingtype) and Valier (feed-type) barley in relation to rumen
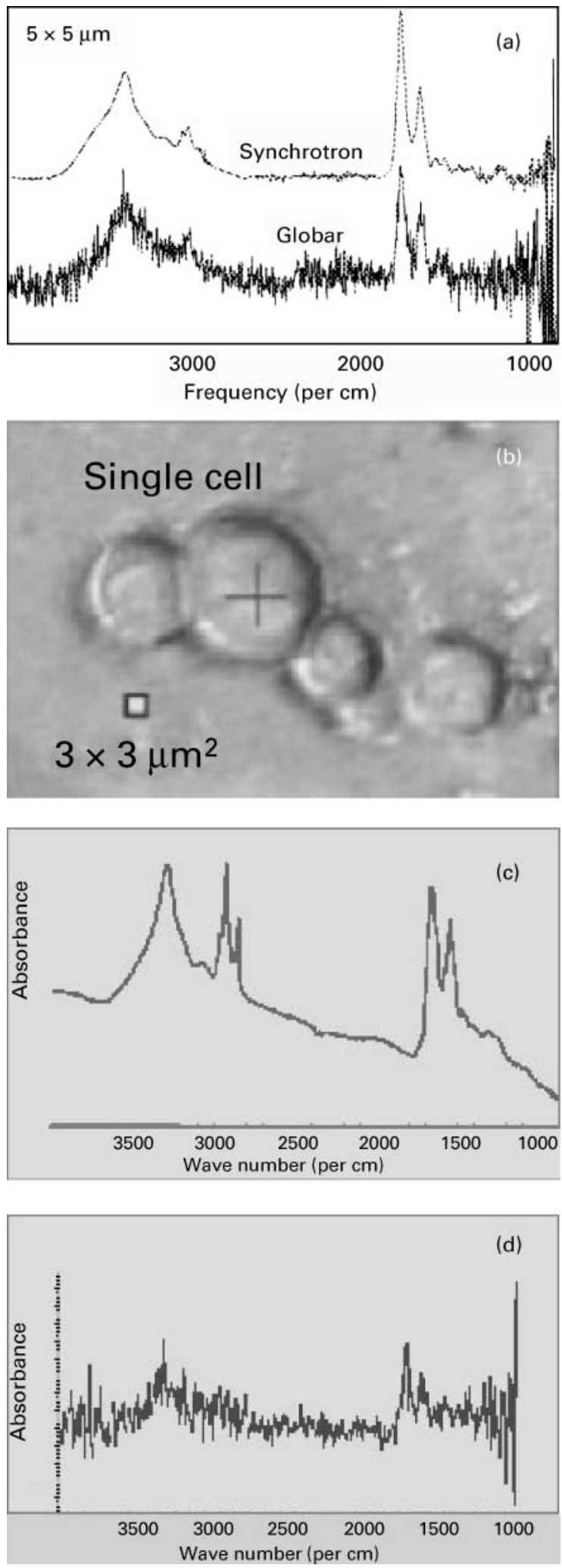

degradation characteristics could be identified. In application 4, chemical features of various feed protein (amide I) secondary structures (such as feather, wheat, oats and barley) could be quantified with a multi-component fitting program (Lorentz function). Finally, the present paper summarises the advantages and disadvantages of the SR-FTIR technique, provides a conclusion and presents implications.

\section{Principle of synchrotron radiation-based Fourier transform infrared microspectroscopy}

\section{Advantages of synchrotron radiation-based Fourier} transform infrared microspectroscopy

Using standard globar (conventional thermal IR)-sourced FTIR microspectroscopy cannot reveal the chemical features of micro-biomaterials $(<35$ to $50 \mu \mathrm{m}$, depending on the type of IR microspectrometer). The normal plantfeed cell size is about $5-30 \mu \mathrm{m}$. With a globar source, a very poor signal:noise ratio within plant cellular dimensions is obtained (Wetzel et al. 1998; Miller et al. 2000; Miller, 2002; Dumas, 2003).

Using SR-FTIR microspectroscopy allows a very small area to be explored; this provides higher accuracy and precision, allows faster data collection, reaches the diffraction limit as a few $\mu \mathrm{m}$ and provides a very good signal:noise ratio with high ultraspatial resolutions (Miller et al. 2000; Holman et al. 2002; Marinkovic et al. 2002; Miller, 2002; Dumas, 2003). It can reveal feed structural-chemical features within cellular dimensions ( $\mathrm{Yu}$ et al. $2003 b, c, 2004 b, c, d)$. Experimentation also shows that the synchrotron IR source is unable to damage any biological tissue.

Detailed comparisons between the conventional globarand synchrotron-sourced FTIR microspectroscopy have been reported (Wetzel et al. 1998; Miller et al. 2000; Holman et al. 2002; Miller, 2002; Dumas, 2003). Fig. 1 (a) shows that with synchrotron light, a very good signal: noise ratio spectrum at a very small area $(5 \mu \mathrm{m} \times 5 \mu \mathrm{m})$ with high ultraspatial resolution can be obtained, compared with a conventional globar source (Miller et al. 2000; Miller, 2002). Fig. 1 (c) shows a faster data collection with synchrotron light. It only needed $16 \mathrm{~s}$ and thirty-two scans to obtain a very good-quality spectrum at a smaller area $(3 \mu \mathrm{m} \times 3 \mu \mathrm{m})$. However, with a conventional globar source (Fig. $1(\mathrm{~d})$ ), at a larger area of $6 \mu \mathrm{m} \times 6 \mu \mathrm{m}$, even

Fig. 1. (a) Comparison of synchrotron and globar Fourier transform IR (FITR) microspectroscopy. With synchrotron light, a very good signal:noise ratio spectrum at a very small area $(5 \mu \mathrm{m} \times 5 \mu \mathrm{m})$ with high ultra-spatial resolution is obtained (top) and with a globar source, a very poor signal:noise ratio spectrum is obtained (bottom) (from Miller et al. 2000; Miller, 2002). (b) Visible image. (c and d) Comparison of synchrotron and globar-sourced FTIR microspectroscopy shows a faster data collection with synchrotron light. With synchrotron light (c), only $16 \mathrm{~s}$ and thirty-two scans are needed to obtain a very-good-quality spectrum at a smaller area $(3 \mu \mathrm{m} \times 3 \mu \mathrm{m})$; with a conventional globar source $(\mathrm{d})$, at a larger area of $6 \mu \mathrm{m} \times 6 \mu \mathrm{m}$, even when using 1000 scans and 500 s only a very poor quality spectrum can be obtained (from Dumas, 2003). 
using 1000 time scans and $500 \mathrm{~s}$, still only a very poorquality spectrum was obtained (Dumas, 2003).

\section{Principle of synchrotron radiation-based Fourier transform infrared analytical technique}

As we know, the total energy of a molecule consists of the translational, rotational, vibrational and electronic energies. Different radiation of the electromagnetic spectrum will result in different energy transitions in a molecule. Organic molecules possess bonds and functional groups. These functional groups vibrate independently of each other and weakly interact as entities. Without any electromagnetic radiation effect, these molecules (functional groups) vibrate independently at their equilibrium position. However, when IR radiation (which is part of the electromagnetic spectrum) is applied to organic molecules (functional groups), it breaks down the molecule's equilibrium (position) stage, and causes two energy transitions in a molecule. It promotes transitions in a molecule between rotational and vibrational energy. When transitions between rotational and vibrational energy levels occur that cause a net change in the dipole moment, the molecule will absorb IR. Therefore an IR absorption profile is unique to a specific molecular vibration frequency (Jackson \& Mantsch, 1996). When IR passes through a sample, some IR is absorbed by the sample and some IR is passed through (transmitted). The resulting spectrum represents the molecular absorption-transmission, which creates a molecular fingerprint of the sample. The identification of molecular functional groups is a major application of IR spectrometry (Hergert, 1971; Joe \& Roth, 1986; Mathlouthi \& Koenig, 1986; Kemp, 1991; Yu et al. 2003c, 2004c).

\section{Unique infrared bands of biological components in feed tissues}

Because biological components have unique molecular chemical-structural features, they have their own unique IR spectrum. The characteristic of protein is unique in the peptide bond. The peptide bond contains $\mathrm{C}=\mathrm{O}$, $\mathrm{C}=\mathrm{N}$ and $\mathrm{N}-\mathrm{H}$. The amide $\mathrm{I}$ bond is primarily $\mathrm{C}=\mathrm{O}$ stretching vibration $(80 \%)$ plus $\mathrm{C}-\mathrm{N}$ stretching vibration. Amide I absorbs at about 1650 per $\mathrm{cm}$. Amide II, which absorbs at 1550 per $\mathrm{cm}$, consists of $\mathrm{N}-\mathrm{H}$ bending vibrations $(60 \%)$ coupled with $\mathrm{C}-\mathrm{N}$ stretching vibrations (40\%). Lipid contains both carbonyl $\mathrm{C}=\mathrm{O}$ ester as well as $\mathrm{CH}_{2}$ and $\mathrm{CH}_{3}$ functional groups. The unique IR spectral profile for lipid is: about 1738 per $\mathrm{cm}$ (carbonyl $\mathrm{C}=\mathrm{O}$ ), 1470 per $\mathrm{cm}$ ( $\mathrm{CH}$ bending), 2961 per $\mathrm{cm}$ (asymmetric stretch $\mathrm{CH}_{3}$ ), 2925 per $\mathrm{cm}$ (asymmetric stretch $\mathrm{CH}_{2}$ ), 2871 per $\mathrm{cm}$ (symmetric stretch $\mathrm{CH}_{3}$ ), and 2853 per $\mathrm{cm}$ (symmetric stretch $\mathrm{CH}_{2}$ ) (Jackson \& Mantsch, 1996). $\mathrm{CHO}$ have lots of sugars, so lots of $\mathrm{OH}$ and $\mathrm{CO}$ bonds. Depending on bond linkage and type of sugar, the IR position for CHO is between 1180 and 950 per $\mathrm{cm}$ (Mathlouthi \& Koenig, 1986) and is attributed to $\mathrm{C}-\mathrm{O}$ stretching vibrations. The bands in this region are very complicated. When studying plant materials, it is customary to look for structural $\mathrm{CHO}$ such as hemicellulose and non-structural CHO such as starch (Wetzel et al. 1998). A peak area at the 1420 per $\mathrm{cm}$ band can be used to look for a particular type of CHO; $\beta$-glucan (Wetzel et al. 1998). In the portion of the spectrum from 1550 to 800 per $\mathrm{cm}$, strong $\mathrm{CHO}$ bands are present for both structural and non-structural $\mathrm{CHO}$, particularly in the region $1100-1025$ per $\mathrm{cm}$. A major difference between these two forms of $\mathrm{CHO}$ is the presence of bands of moderate intensity at approximately 1420, 1370 and 1335 per $\mathrm{cm}$, which indicates the characteristics of structural CHO (Wetzel et al. 1998; Wetzel, 2001). CHO band peaks between 1100 and 1025 per $\mathrm{cm}$ depend on whether the $\mathrm{CHO}$ is structural or nonstructural. A peak at about 1025 per $\mathrm{cm}$ indicates nonstructural CHO such as starch in the endosperm of cereal grain (Wetzel et al. 1998; Wetzel, 2001). The same principle applies for other biological components, such as lignin at 1510 per $\mathrm{cm}$, hemicellulose at 1246 per $\mathrm{cm}$, cellulose at 1100 per $\mathrm{cm}$ and starch at 1025 per cm (Himmelsbach et al. 1998; Miller et al. 1998, 2000; Wetzel et al. 1998; Wetzel, 2001; Marinkovic et al. 2002; Miller, 2002; Yu et al. 2004c). Detailed discussions on functional group assignments in plant materials have been reported by Wetzel et al. (1998), Raab \& Martin (2001), Wetzel (2001) and Yu et al. $(2004 c, d)$.

\section{Materials and methodology of synchrotron radiation- based Fourier transform infrared technique}

\section{Feed preparation and synchrotron transmission and reflection infrared microspectroscopy}

The feed samples were frozen at $-20^{\circ} \mathrm{C}$ on objective disks in a cryostatic microtome and then were cut into thin crosssections (about 5 to $10 \mu \mathrm{m}$ thickness). The unstained crosssections of the feed tissues were rapidly transferred to $\mathrm{BaF}_{2}$ windows (size $13 \times 1 \mathrm{~mm}$ disk; Spectral Systems, Hopwell Junction, NY, USA) for transmission mode in synchrotron transmission FTIR microspectroscopic work. The unstained cross-sections were dry-mounted onto Low-e IR microscope slides (Kevley Technologies, Chesterland, $\mathrm{OH}$, USA) for reflectance mode in synchrotron reflection FTIR microspectroscopic work. More detailed methodology on slide preparation has been reported by $\mathrm{Yu}$ et al. $(2003 c, 2004 a, b, c, d)$.

\section{Synchrotron light source}

The experiments were performed at the National Synchrotron Light Source in Brookhaven National Laboratory (NSLS-BNL; US Department of Energy, New York, NY, USA) and the Synchrotron Radiation Center (SRC; University of Wisconsin, Madison, WI, USA).

\section{Synchrotron radiation-based Fourier transform infrared microspectroscopy}

The spectroscopic images were recorded using a Nicolet Magna 860 FTIR (Thermo Nicolet Instruments, Madison, WI, USA) equipped with a Continuum IR microscope (Spectra Tech, Oak Ridge, TN, USA), mapping stage controller, $32 \times$ objective and a mercury cadmium telluride (MCT-A) detector. The bench was configured with a 
collimated synchrotron light beamline (U2B and U10B at the NSLS-BNL; port 031 at the SRC) which served as an external input to the Nicolet Magna 860. The modulated light was passed through the IR microscope to perform transmission or reflection microscopy. The spectra were collected in the mid-IR range of $4000-800$ per $\mathrm{cm}$ at a resolution of 4 per $\mathrm{cm}$ with sixty-four scans co-added and an aperture setting of about $10 \mu \mathrm{m} \times 10 \mu \mathrm{m}$. The reasons for the chosen aperture size of $10 \mu \mathrm{m} \times 10 \mu \mathrm{m}$ were: (1) the size was within cellular dimensions; (2) the $10 \mu \mathrm{m} \times 10 \mu \mathrm{m}$ aperture size was the best for getting a good signal:noise ratio spectrum mapping of feed tissues. To minimise IR absorption by $\mathrm{CO}_{2}$ and water vapour in the ambient air, the optics were purged using dry $\mathrm{N}_{2}$. A background spectroscopic image file was collected from an area free of sample. The mapping steps were equal to aperture size. Stage control, data collection and processing were performed using OMNIC 6.0 (Thermo-Nicolet, Madison, WI, USA). Scanned visible images were obtained using a charge-coupled-device camera linked to the IR images (Yu et al. 2003c, 2004a,b,c).

In the microspectroscopic area mapping, the spatial information was obtained by translating the tissue along the $x$ and $y$ axes, and positioning different parts of the designated tissues in the synchrotron IR beam of the microspectroscope. The motorised computer-control stage was programmed to trace the designated areas in the tissues. After measuring the spectra of all parts of interest, the spectral information was related to the visible images. As a result, spectral datasets were formed with the $x y$ surface, corresponding to the scanned area of the sample, and $z$ direction, which contained the spectral information. Functional group images (such as amide I, aromatic compound, carbonyl ester) were generated by plotting the intensity of the synchrotron IR absorption bands as a function of $x y$ position (Budevska, 2002). Different coverage of the sample with measurements could also be achieved by varying the step size and the dimensions of the image mask (aperture size).

\section{Data analysis and chemical imaging}

The spectral data of the feed tissue were collected, corrected with the background spectrum, displayed in the absorbance mode and analysed using OMNIC software 6.0 (ThermoNicolet, Madison, WI, USA). An automatic baseline correction was applied to generate the final spectra. The synchrotron FTIR absorbance was expressed as $\log (1 / \mathrm{R})$ (The unit of the spectrum collected in the reflectance mode needed to be converted to absorbance units by $\log (1 / \mathrm{R})$.) The data can be displayed either as a series of spectroscopic images collected at individual wavelengths, or as a collection of IR spectra obtained at each pixel position in the image. Functional group bands were according to reports (Jackson \& Mantsch, 1996; Himmelsbach et al. 1998; Wetzel et al. 1998; Miller et al. 2000; Wetzel, 2001; Miller, 2002). Chemical imaging of functional groups was determined by OMNIC software 6.0 (Thermo-Nicolet, Madison, WI, USA) or by IR spectral imaging software, version. 1.1.01 (Cytospec Inc., Croton-on-Hudson, NY, USA). Peak ratio images were obtained by the height or area under one functional group band (such as amide I; 1650 per $\mathrm{cm}$ ) divided by the height or area under another functional group band (such as starch; 1025 per $\mathrm{cm}$ ) at each pixel (pixel size $10 \times 10 \mu \mathrm{m}$ ), which represented the biological component ratio intensity and distribution in the feed tissue (for example, protein:total starch ratio image and hemicellulose:total $\mathrm{CHO}$ ratio image). The false colour maps were used, which were derived from the area under particular spectral features.

\section{Univariate and multivariate statistical approaches for chemical mapping}

Statistical approaches to analyse spectral data collected with SR-FTIR microspectroscopy usually include uni- and multivariate statistical methods. The univariate methods of analysis consist of various mapping displays of spectral data. Usually researchers may select band intensities, integrated intensities, band frequencies, band intensity ratios etc., to construct false colour maps of the spectral data (Miller, 2002). The multivariate methods of data analysis create spectral corrections and maps by including not just one intensity or frequency point of a spectrum, but by utilising the entire spectral information. The methods include cluster analysis (Cytospec, 2004), which is a technique that clusters IR spectra in a map based on similarity with other spectra in the same map (Miller, 2002).

\section{Hierarchical cluster analysis}

An agglomerative hierarchical cluster analysis was used to perform a cluster analysis of IR spectra datasets and displayed the results of cluster analysis as images and as dendrograms (Cytospec, 2004) when a biological component band has more or less interference with other bands. For cluster analysis, Ward's algorithm was used for clustering. Spectral distances were computed as D-values. In a dendrogram, spectral distances were given on the $y$ axis. Horizontal lines illustrated the merging process, for example the combination of two clusters to a new cluster of spectra.

\section{Statistical analysis}

The statistical analysis was performed using SAS procedures (SAS Institute, Inc., 1998).

\section{Applications of synchrotron radiation-based infrared microspectroscopy to feed science and animal nutrition}

Application 1: chemical imaging of microstructures of feed tissues within cellular dimensions using synchrotron radiation-based transmission Fourier transform infrared microspectroscopy

The objectives of these studies (Yu et al. 2003c, 2004b) were to use this non-invasive bioanalytical technique (SR-FTIR) to chemically image the intrinsic structures of feed tissues at an ultraspatial resolution to reveal the plant-feed structural-chemical information. The experiments were performed at the beamline U10B of the NSLS-BNL (US Department of Energy, New York).

The results showed that with the extremely bright synchrotron light, the spectra with a high signal:noise ratio 
were obtained from areas as small as $10 \mu \mathrm{m} \times 10 \mu \mathrm{m}$ in the plant-feed tissue, which allowed us to 'see' feed tissue in a chemical sense on a cellular level (Figs. 2, 3 and 4). The ultraspatially resolved imaging of feed tissues by stepping in pixel-sized increments was obtained. Chemical intensities and distributions of biological components such as lignin, cellulose, protein, lipid and total $\mathrm{CHO}$ and their ratios could be mapped (Figs. 2, 3 and 4) (Yu et al. $2003 c, 2004 c$ ). These images revealed the chemical information of feed intrinsic structure.

When a unique band had interference with other bands, cluster analysis gave satisfactory results and was conclusive in showing that it could discriminate and classify functional group differences existing in different structure regions of feed. For example, in maize tissue, spectral data (Fig. 5) show that the band at about 1515 per $\mathrm{cm}$ has inference with part of the amide II band. A cluster image (Fig. 6) proved that the clusters in the pericarp region and endosperm region are completely different.
In conclusion from the studies (Yu et al. 2003c, 2004b), the SR-FTIR technique can provide chemical and functional characteristics of feed tissue at high ultraspatial resolutions. The SR-FTIR microspectroscopic images can generate spatially localised chemical information within cellular dimensions. This work clearly shows that imaging chemical and functional group distribution across feed tissue can be accomplished using FTIR microspectroscopy powered by synchrotron bright light. Such information could be analysed for clues of the plant intrinsic structures in relation to biodegradation characteristics in animals.

Application 2: ultrastructural-chemical makeup of yellow- and brown-seeded Brassica rape, explored with synchrotron reflection Fourier transform infrared microspectroscopy

Brassica rape including the yellow-seeded Brassica rapa and the dark-brown-seeded B. napus varieties are commonly grown in Western Canada. Yellow-seeded rape
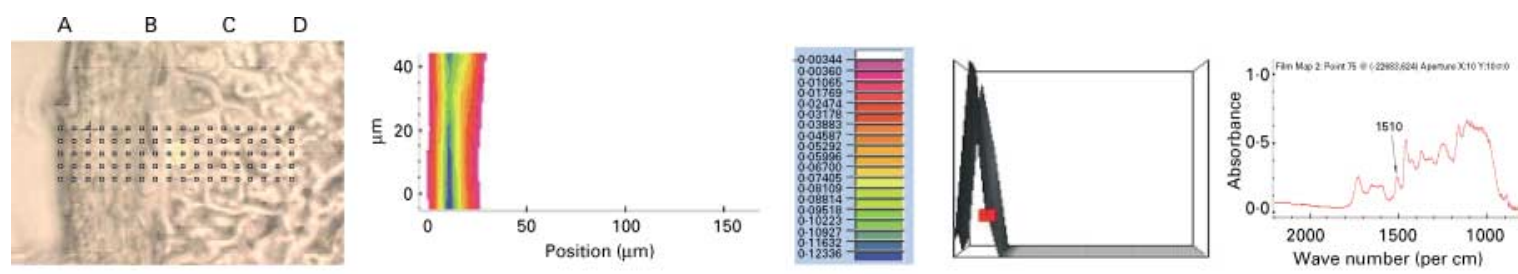

(a)
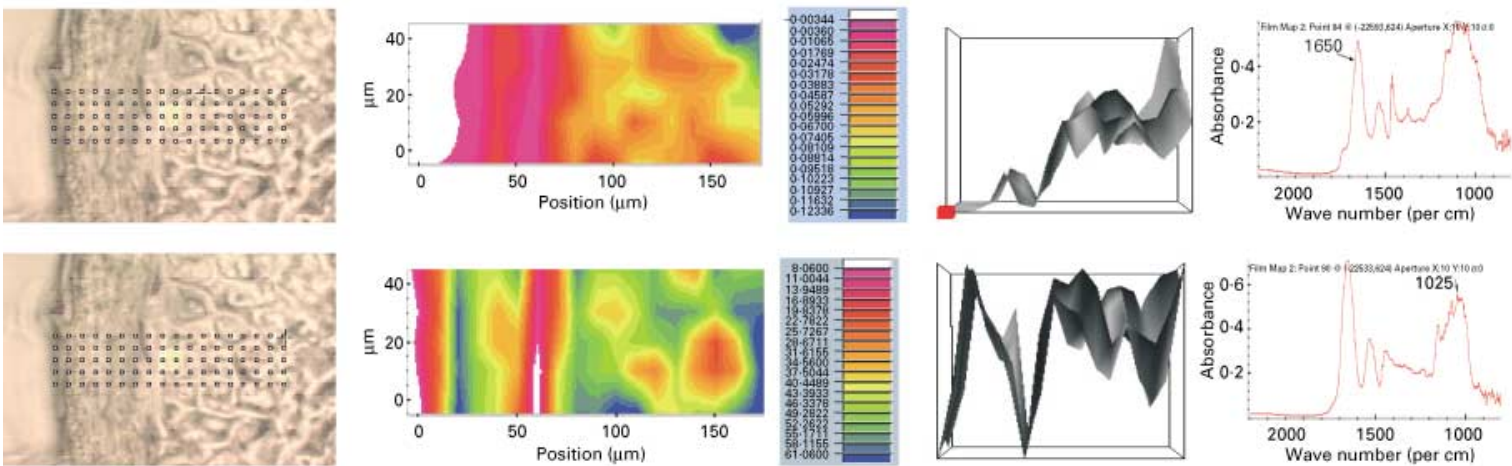

(c)
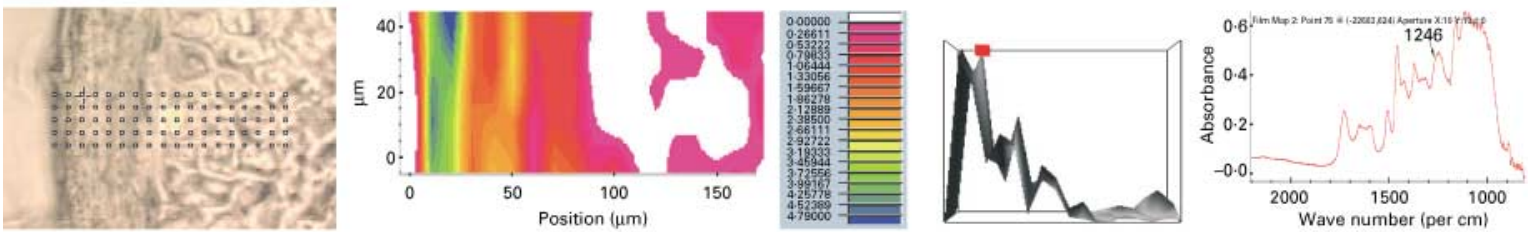

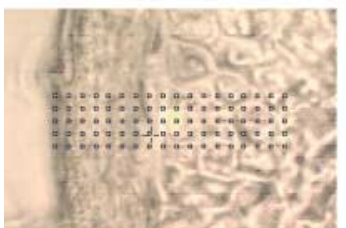

(1)

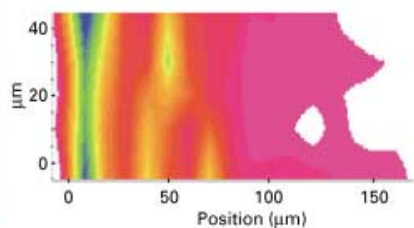

(2)

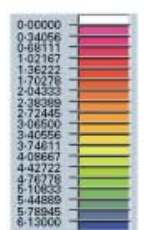

(3)

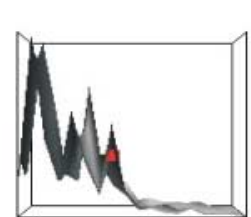

(4)

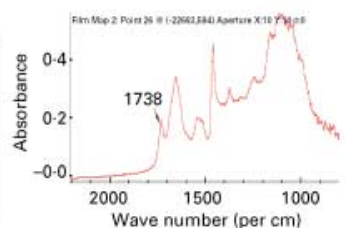

(5)

Fig. 2. Functional-group images of Harrington barley tissue within cellular dimensions from the pericarp (A), seed coat $(B)$, aleurone layer $(C)$ and endosperm (D). (1), Visible image; (2), chemical image; (3), chemical intensity ruler; (4), three-dimensional image; (5), spectra corresponding to the pixel at the cross-hair in the visible image. (a) Area under peaks centred at 1510 per cm showing lignin distribution and intensity; (b) area under 1650 per $\mathrm{cm}$ (amide I) showing protein distribution and intensity; (c) area under the peaks between 1180 and 1000 per cm (carbohydrates); (d) area under peaks at 1246 per $\mathrm{cm}$ indicating cellulosic material distribution and intensity; (e) area under peaks at 1738 per $\mathrm{cm}(\mathrm{C}=\mathrm{O}$ ester linkage) showing lipid distribution and intensity. (From Yu et al. 2003 c.) 
A $\quad$ B $\quad$ C $\quad$ D
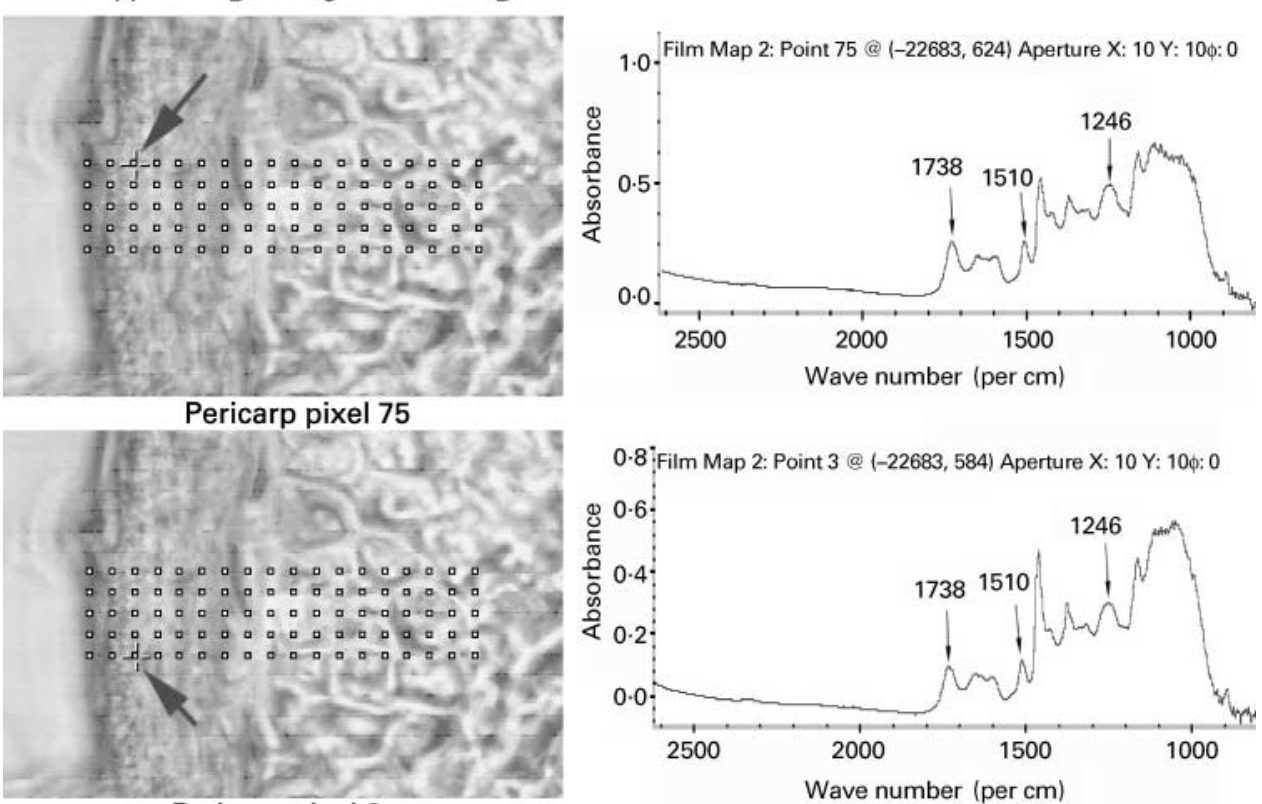

Pericarp pixel 3
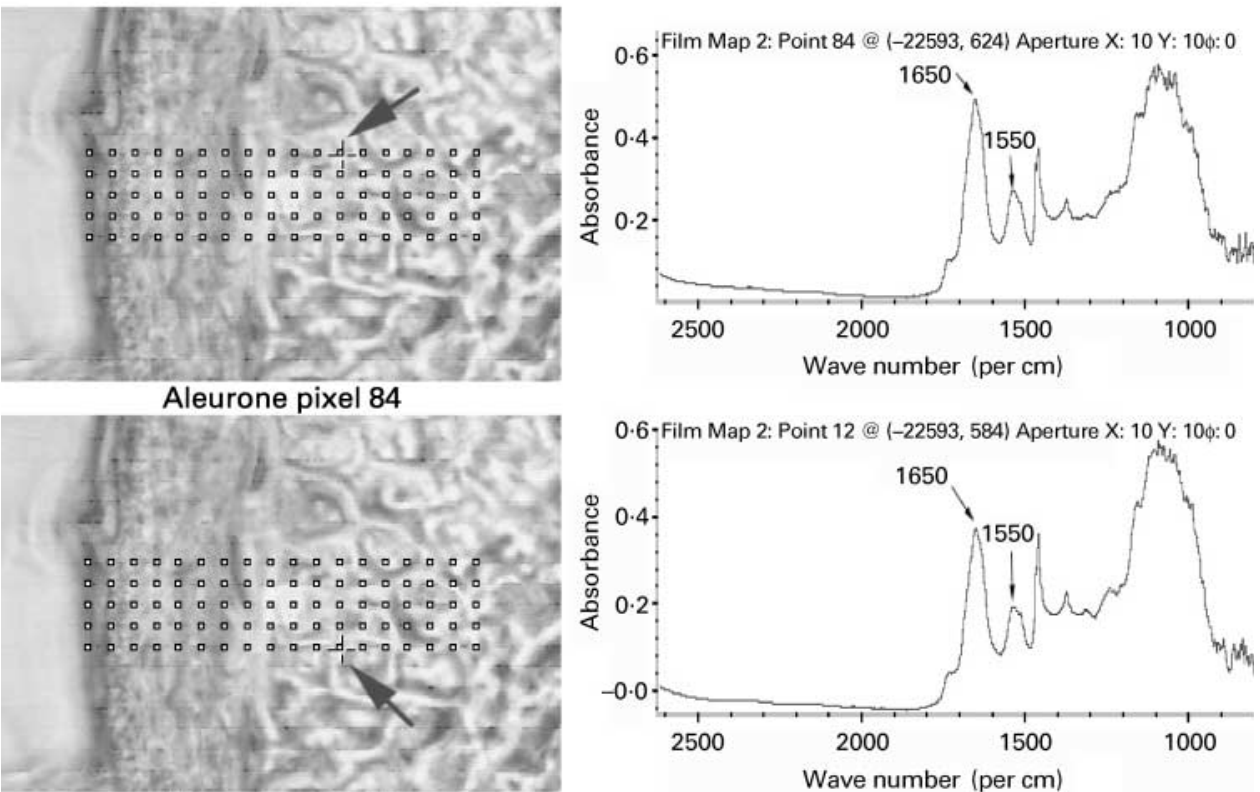

Aleurone pixel 12

Fig. 3. Spectra of pericarp $(A)$ and aleurone layer $(C)$ of Harrington barley tissue selected from the corresponding area from the visible images, showing that similar morphological parts exhibit similar spectral characteristics and chemical composition. (B) Seed Coat, (D) endosperm. (From Yu et al. 2003 c.)

has been reported to be lower in fibre than those of brownseeded types (Stringam et al. 1974; Slominski et al. 1994; Simbaya et al. 1995). Rapeseed selection programmes have been directed toward increased yellow seed content to decrease fibre content and thereby increase nutritive value (Slominski et al. 1994; Simbaya et al. 1995). Several studies have focused on the total chemical composition of rapeseeds including total protein, $\mathrm{CHO}$ and dietary fibre components using traditional 'wet' chemical analysis (Slominski et al. 1994; Simbaya et al. 1995). No research has been carried out to study the ultrastructural chemical makeup features (chemical bonding and functional groups) of rapeseed tissue within cellular dimensions. These features are associated with rapeseed quality and nutritive value in man and animals.

The objective of this study (Yu et al. 2004a) was to use synchrotron reflection FTIR microspectroscopy as a nondestructive technique to explore the ultrastructural-chemical makeup (functional groups and bonding characteristics) of yellow- (B. rapa cv. Klondike) and brown-seeded (B. napus cv. Bounty) rape at an ultraspatial resolution. The investigated chemical bonding and functional groups included the $\mathrm{NH}+\mathrm{OH}$ group with a broad band at about 3298 per $\mathrm{cm}, \mathrm{CH}$ groups $\left(\mathrm{CH}_{3}\right.$ asymmetric stretch at 
(a)

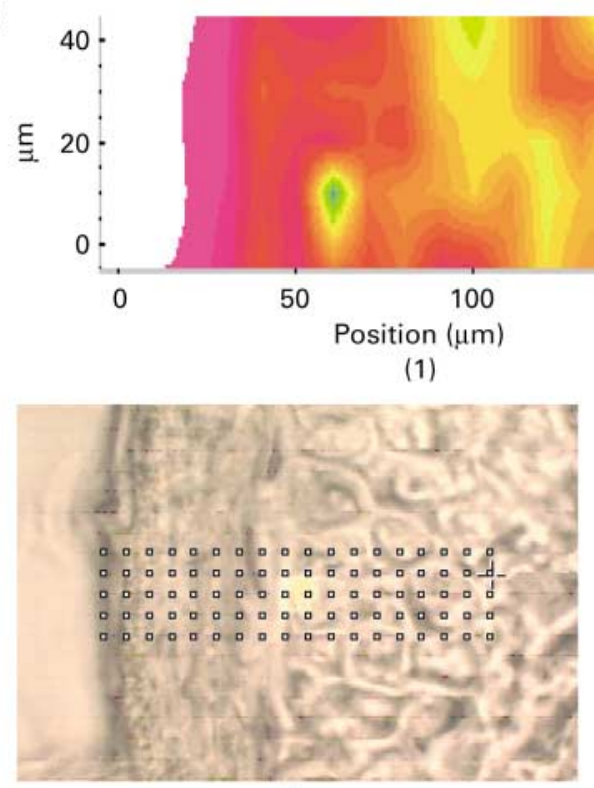

(4)

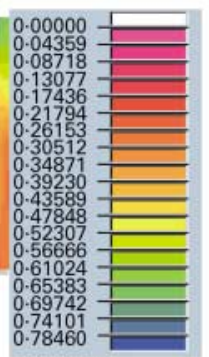

(2)

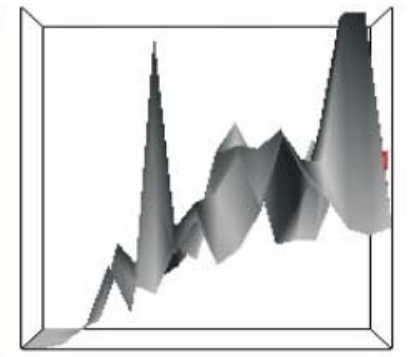

(3)

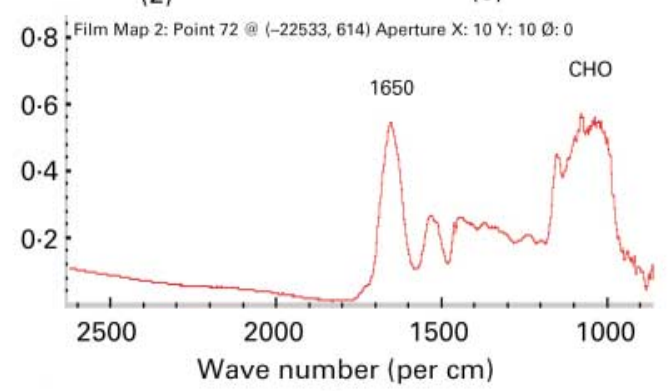

(5)

(b)

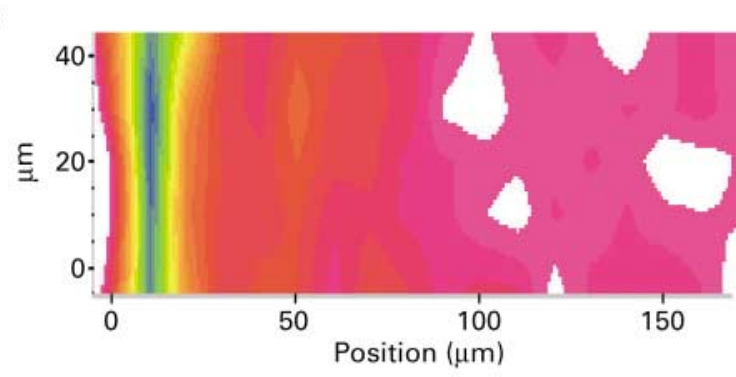

(1)

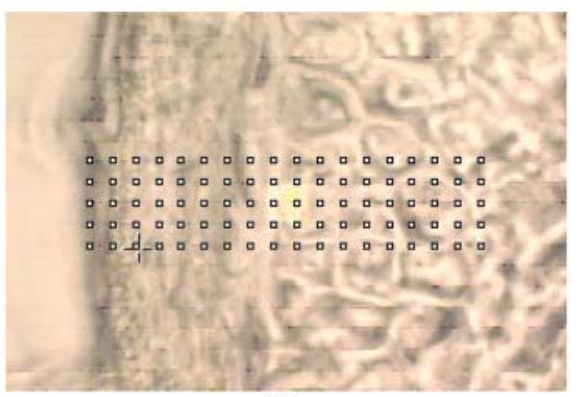

(4)

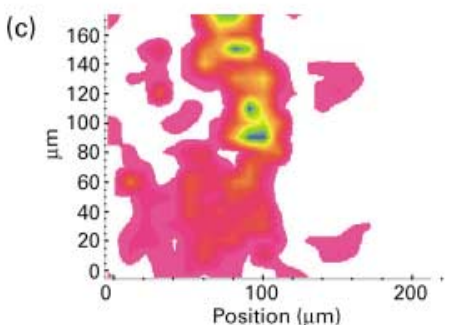

(1)

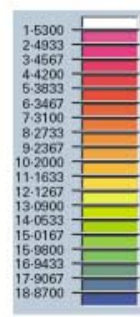

(2)

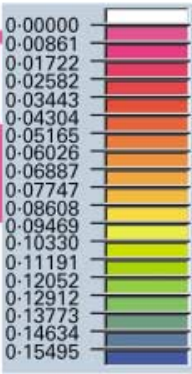

(2)

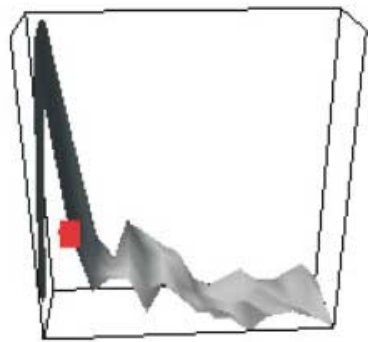

(3)

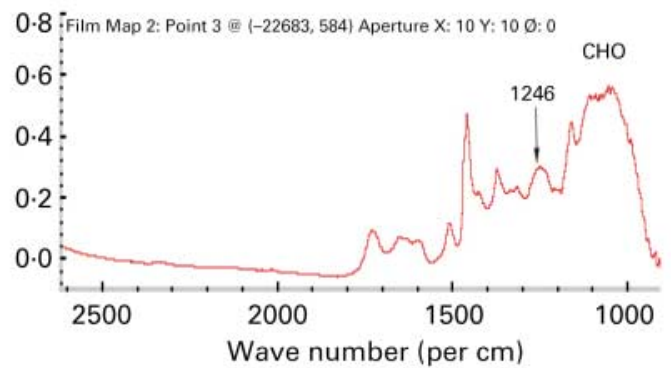

(5)

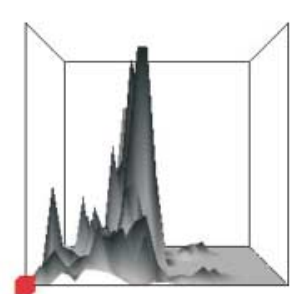

(3)

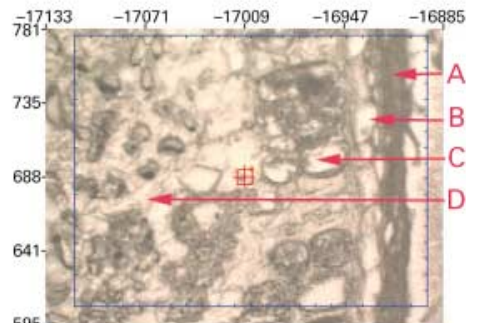

(4)

Fig. 4. (a) Peak area ratio, area under the 1650 per $\mathrm{cm}$ band divided by the area under the peaks between 1180 and 1000 per $\mathrm{cm}$ at each pixel, representing protein:total carbohydrate ratio in Harrington barley seed. (b) Peak area ratio, area under the 1246 per $\mathrm{cm}$ band divided by the area under the peaks between 1180 and 1000 per $\mathrm{cm}$ at each pixel, representing hemicellulose:total carbohydrate ratio in Harrington barley seed. (c) Peak height ratio, representing protein:total starch ratio in Valier barley tissue, obtained by the height under the 1650 per $\mathrm{cm}$ band divided by the height under the peaks 1025 per $\mathrm{cm}$ at each pixel. (1), Chemical image; (2), chemical intensity ruler; (3), three-dimensional image; (4), visible image; (C) (4) shows the visible bright field image of the mapped area outlined by the lined box, from pericarp (A), seed coat (B), aleurone layer (C) and endosperm area (D). (5), spectra corresponding to the pixel at the cross-hair in the visible image. (From Yu et al. 2004 C.) 

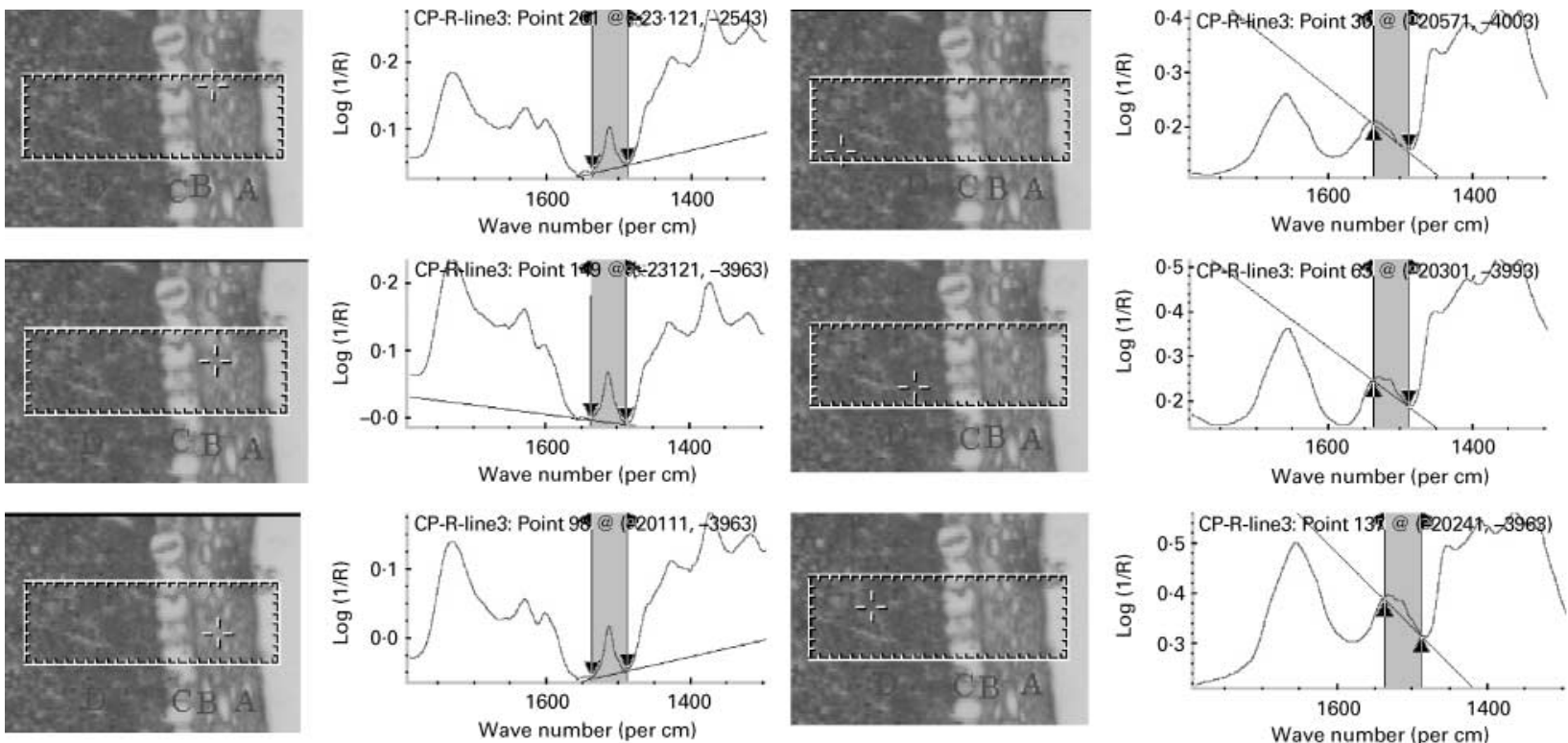

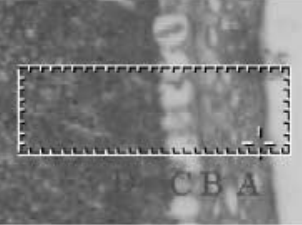

Pericarp region

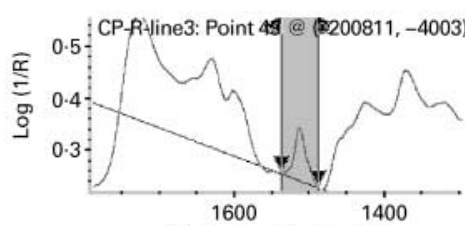

Wave number (per $\mathrm{cm}$ ) Region: 1538.94 to 1490.73 Baseline: 1538.94 to 1490.73

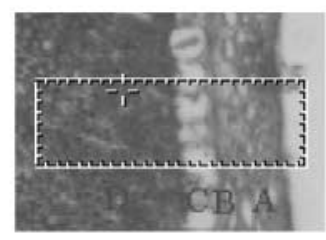

Endosperm region

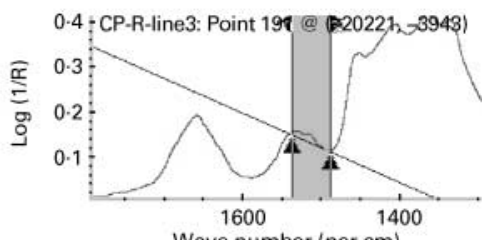

Wave number (per $\mathrm{cm}$ )

Region: $1538.94 \quad 1490.73$

Baseline: $1538.94 \quad 1490.73$

Fig. 5. Spectra of pericarp and endosperm of maize tissue selected from pixels from the visible images, showing that the area under the 1515 per $\mathrm{cm}$ peak (aromatic compound) in the pericarp from lignin imaging (see left spectrum) covering part of the amide II band in the endosperm (right spectrum), indicating lignin imaging under the 1515 per cm peak having interference with part of the amide II band.
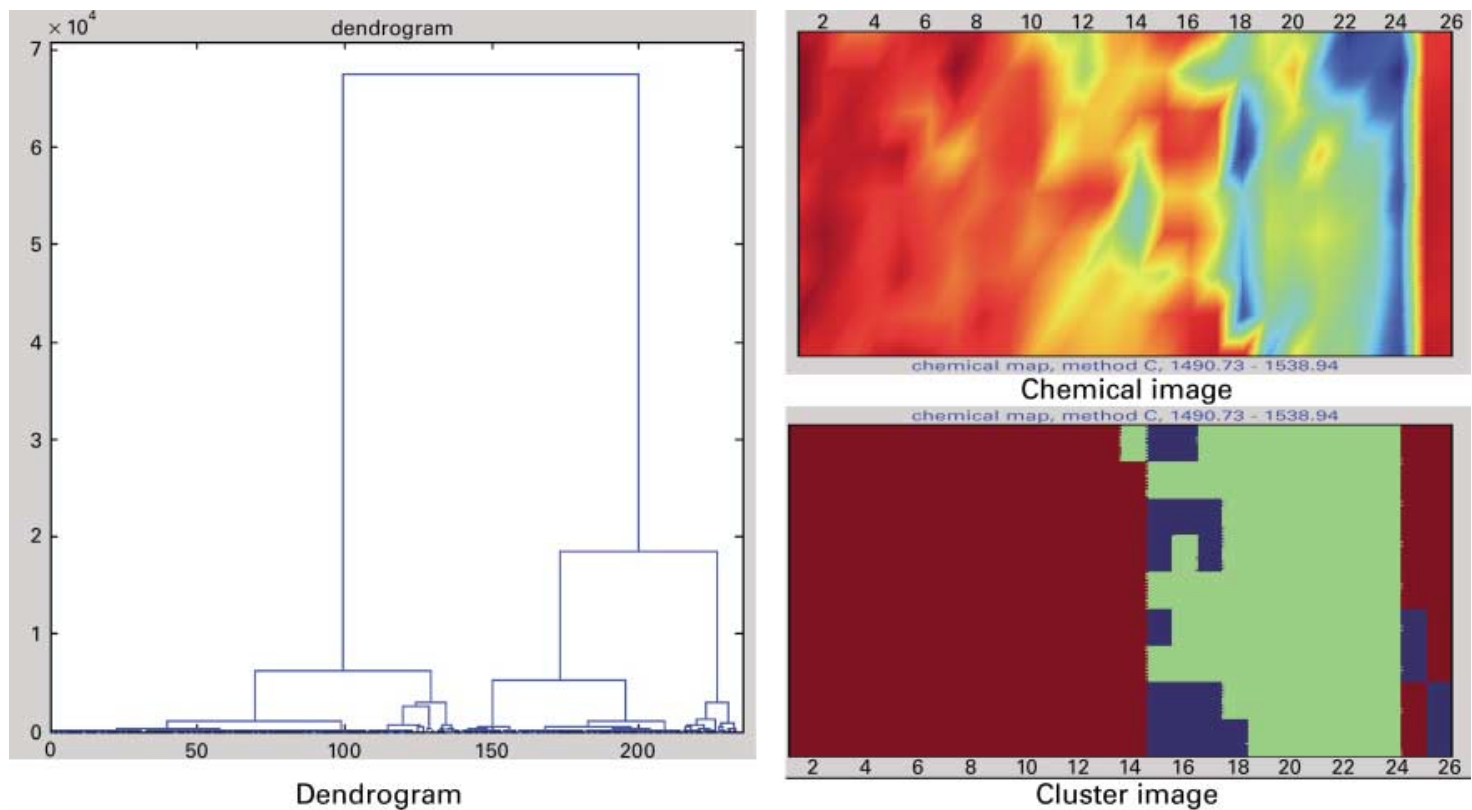

Fig. 6. Cluster image of lignin clearly showing that the clusters in the pericarp region and endosperm region are different. Cluster analysis is as follows: (1) select spectral analysis region, 1538.94 to 1490.73 per cm; (2) distance method: D-values; (3) cluster method: Ward's algorithm; (4) number of clusters (three in cluster image). 
Table 1. Synchrotron-based Fourier transform infrared absorbed peak height of $\mathrm{CH}$ functional groups: $\mathrm{CH}_{3}$ asymmetric stretching, $\mathrm{CH}_{2}$ asymmetric stretching, $\mathrm{CH}_{3}$ symmetric stretching, and $\mathrm{CH}_{2}$ symmetric stretching vibrations in the microstructure (10 $\times 10 \mu \mathrm{m}$ ) of yellow- (Brassica rapa) and brown-seeded (B. napus) rape

(Least squares means, standard errors and ranges)

\begin{tabular}{|c|c|c|c|c|c|c|c|c|}
\hline & \multicolumn{8}{|c|}{$\mathrm{CH}$ functional group (IR absorption units) } \\
\hline & \multicolumn{2}{|c|}{$\begin{array}{l}\mathrm{CH}_{3} \text { asymmetric } \\
\text { stretching }\end{array}$} & \multicolumn{2}{|c|}{$\begin{array}{l}\mathrm{CH}_{2} \text { asymmetric } \\
\text { stretching }\end{array}$} & \multicolumn{2}{|c|}{$\begin{array}{l}\mathrm{CH}_{3} \text { symmetric } \\
\text { stretching }\end{array}$} & \multicolumn{2}{|c|}{$\begin{array}{l}\mathrm{CH}_{2} \text { symmetric } \\
\text { stretching }\end{array}$} \\
\hline & Mean & SE & Mean & SE & Mean & SE & Mean & SE \\
\hline $\begin{array}{l}\text { Wave number (per } \mathrm{cm} \text { ) } \\
\text { Yellow-seed rape (B. rapa) }\end{array}$ & \multicolumn{2}{|c|}{2958} & \multicolumn{2}{|c|}{2928} & \multicolumn{2}{|c|}{2873} & \multicolumn{2}{|c|}{2851} \\
\hline$n$ & \multicolumn{2}{|c|}{50} & \multicolumn{2}{|c|}{50} & \multicolumn{2}{|c|}{50} & \multicolumn{2}{|c|}{50} \\
\hline Mean & 0.061 & 0.004 & 0.090 & 0.015 & 0.052 & 0.004 & 0.045 & 0.012 \\
\hline Range & 0.009 & $0 \cdot 130$ & 0.010 & 0.790 & 0.013 & $0 \cdot 145$ & 0.004 & 0.641 \\
\hline \multicolumn{9}{|l|}{ Brown-seed rape (B. napus) } \\
\hline$n$ & \multicolumn{2}{|c|}{36} & \multicolumn{2}{|c|}{36} & \multicolumn{2}{|c|}{36} & \multicolumn{2}{|c|}{36} \\
\hline Mean & 0.056 & 0.005 & 0.087 & 0.018 & 0.048 & 0.005 & 0.043 & 0.014 \\
\hline Range & 0.021 & 0.106 & 0.018 & 0.309 & 0.013 & 0.100 & 0.004 & 0.227 \\
\hline Pooled SEM & \multicolumn{2}{|c|}{0.0046} & \multicolumn{2}{|c|}{0.0162} & \multicolumn{2}{|c|}{0.0043} & \multicolumn{2}{|c|}{0.0132} \\
\hline$P$ value & \multicolumn{2}{|c|}{0.46} & \multicolumn{2}{|c|}{0.91} & \multicolumn{2}{|c|}{0.52} & \multicolumn{2}{|c|}{0.92} \\
\hline
\end{tabular}

about 2961 per cm; $\mathrm{CH}_{2}$ asymmetric stretch at about 2925 per $\mathrm{cm} ; \mathrm{CH}_{3}$ symmetric stretch at about 2871 per $\mathrm{cm} ; \mathrm{CH}_{2}$ symmetric stretch at about 2853 per $\mathrm{cm}$ ), amide I at about 1650 per $\mathrm{cm}$, carbonyl $\mathrm{C}=\mathrm{O}$ ester stretch at about 1740 per $\mathrm{cm}$, and hemicellulose at about 1240 per $\mathrm{cm}$ and total $\mathrm{CHO}$ at about $1180-900$ per $\mathrm{cm}$ as well as their ratios (Table 1; Wetzel \& LeVine, 1999; Jackson \& Mantsch, 1996). The experiment was performed at the U10B station of the NSLS-BNL (US Department of Energy, New York).

The results showed two IR absorbed intensities of $\mathrm{CH}_{3}$ asymmetric stretching of 0.061 and $0.056, \mathrm{CH}_{2}$ asymmetric stretching of 0.090 and $0.087, \mathrm{CH}_{3}$ symmetric stretching of 0.052 and 0.048 , and $\mathrm{CH}_{2}$ symmetric stretching of 0.045 and 0.043 for the yellow- and brown-seeded rape, respectively (Table 1). The ratios of total $\mathrm{CH}_{2}: \mathrm{CH}_{3}, \mathrm{CH}_{3}$ asymmetric: $\mathrm{CH}_{3}$ symmetric, $\mathrm{CH}_{2}$ asymmetric: $\mathrm{CH}_{2}$ symmetric and total $\mathrm{CH}$ asymmetric: $\mathrm{CH}$ symmetric were 1.06 and $1.13,1.28$ and $1.26,2.90$ and $3.08,1.82$ and 1.78 , for the yellow- and brown-seeded rape, respectively. There were no differences between the two rapeseed types in the content and ratios of $\mathrm{CH}$ groups $\left(\mathrm{CH}_{2}\right.$ and $\left.\mathrm{CH}_{3}\right)$ of the scanned areas, indicating that lipid chain length and branching is similar between the two seed types. The absorbed intensities of peak area of $\mathrm{NH}+\mathrm{OH}$, total $\mathrm{CH}$, carbonyl $\mathrm{C}=\mathrm{O}$, amide $\mathrm{I}$, hemicellulose, and total $\mathrm{CHO}$ were 101.623 and $87.123,8.522$ and $7.406,0.386$ and $0.414,39.200$ and $31.045,1.445$ and $1.329,36.450$ and $24.199(P<0.01)$, for the yellow- and brown-seeded rape, respectively. There were significant differences in amide I and total $\mathrm{CHO}$, indicating different microstructural protein (peptide $\mathrm{C}=\mathrm{O}$ bonding) and $\mathrm{CHO}$ makeup between the two rapeseed types (Tables 2 and 3 ).

The results also show differences in the ratios of total $\mathrm{NH}+\mathrm{OH}: \mathrm{CHO}(2.85$ v. $3.84 ; P<0.01), \mathrm{CH}: \mathrm{CHO}(0.23$ v. $0.32 ; \quad P<0.01)$, amide $\mathrm{I}: \mathrm{NH}+\mathrm{OH}(0.48$ v. 0.37 ; $P=0.07)$, amide I:hemicellulose $(P=0.09)$, hemicellulose: CHO (0.039 v. 0.059; $P<0.001)$, and CHO:amide I $(1.11$ v. $0.84 ; P=0.051)$ between the yellow- and brown-seeded

Table 2. Synchrotron-based Fourier transform infrared (FTIR) absorbed peak area and peak height (IR absorption units) of chemical functional groups in the microstructure $(10 \times 10 \mu \mathrm{m})$ of yellow- (Brassica rapa) and brown-seeded (B. napus) rape (from Yu et al. 2004a) (Least squares means, standard errors and ranges)

\begin{tabular}{|c|c|c|c|c|c|c|c|c|c|c|c|c|}
\hline \multirow{3}{*}{$\begin{array}{l}\text { FTIR absorbed } \\
\text { intensity }\end{array}$} & \multicolumn{4}{|c|}{$\mathrm{NH}+\mathrm{OH}$} & \multicolumn{4}{|c|}{$\mathrm{CH}$} & \multicolumn{4}{|c|}{ Carbonyl $\mathrm{C}=\mathrm{O}$ ester } \\
\hline & \multicolumn{2}{|c|}{ Peak area } & \multicolumn{2}{|c|}{ Peak height } & \multicolumn{2}{|c|}{ Peak area } & \multicolumn{2}{|c|}{ Peak height } & \multicolumn{2}{|c|}{ Peak area } & \multicolumn{2}{|c|}{ Peak height } \\
\hline & Mean & SE & Mean & SE & Mean & SE & Mean & SE & Mean & SE & Mean & SE \\
\hline $\begin{array}{l}\text { Approximate wave } \\
\text { number (per } \mathrm{cm} \text { ) }\end{array}$ & \multicolumn{4}{|c|}{3298} & \multicolumn{4}{|c|}{2927} & \multicolumn{4}{|c|}{1740} \\
\hline \multicolumn{13}{|c|}{ Yellow-seed rape (B. rapa) } \\
\hline$n$ & \multicolumn{2}{|c|}{50} & \multicolumn{2}{|c|}{50} & \multicolumn{2}{|c|}{50} & \multicolumn{2}{|c|}{50} & \multicolumn{2}{|c|}{50} & \multicolumn{2}{|c|}{50} \\
\hline Mean & 101.623 & $6 \cdot 228$ & 0.393 & 0.025 & 8.522 & 0.883 & 0.088 & 0.014 & 0.386 & 0.072 & 0.013 & 0.002 \\
\hline Range & 9.030 & 221.703 & 0.025 & 0.890 & $1 \cdot 197$ & 44.089 & 0.011 & 0.790 & 0.024 & 0.862 & 0.002 & 0.035 \\
\hline \multicolumn{13}{|c|}{ Brown-seed rape (B. napus) } \\
\hline$n$ & \multicolumn{2}{|c|}{36} & \multicolumn{2}{|c|}{36} & \multicolumn{2}{|c|}{36} & \multicolumn{2}{|c|}{36} & \multicolumn{2}{|c|}{36} & \multicolumn{2}{|c|}{36} \\
\hline Mean & $87 \cdot 123$ & 7.587 & 0.339 & 0.030 & 7.406 & 1.076 & 0.086 & 0.017 & 0.414 & 0.086 & 0.013 & 0.002 \\
\hline Range & 29.761 & $167 \cdot 124$ & 0.150 & 0.659 & $2 \cdot 131$ & $19 \cdot 347$ & 0.023 & 0.293 & 0.003 & 3.491 & 0.001 & 0.062 \\
\hline Pooled SEM & \multicolumn{2}{|c|}{6.9412} & \multicolumn{2}{|c|}{0.0275} & \multicolumn{2}{|c|}{0.9842} & \multicolumn{2}{|c|}{0.0160} & \multicolumn{2}{|c|}{0.0792} & \multicolumn{2}{|c|}{0.0019} \\
\hline$P$ value & \multicolumn{2}{|c|}{0.14} & \multicolumn{2}{|c|}{0.17} & \multicolumn{2}{|c|}{0.43} & & & & & & \\
\hline
\end{tabular}


Table 3. Synchrotron-based Fourier transform infrared (FTIR) absorbed peak area and peak height of chemical functional groups in the microstructure $(10 \times 10 \mu \mathrm{m})$ of yellow- (Brassica rapa) and brown-seeded (B. napus) rape (IR absorption units) (Least squares means, standard errors and ranges)

\begin{tabular}{|c|c|c|c|c|c|c|c|c|c|c|c|c|}
\hline \multirow{3}{*}{$\begin{array}{l}\text { FTIR absorbed } \\
\text { intensity }\end{array}$} & \multicolumn{4}{|c|}{ Amide I } & \multicolumn{4}{|c|}{ Hemicellulose } & \multicolumn{4}{|c|}{ Carbohydrate } \\
\hline & \multicolumn{2}{|c|}{ Peak area } & \multicolumn{2}{|c|}{ Peak height } & \multicolumn{2}{|c|}{ Peak area } & \multicolumn{2}{|c|}{ Peak height } & \multicolumn{2}{|c|}{ Peak area } & \multicolumn{2}{|c|}{ Peak height } \\
\hline & Mean & SE & Mean & SE & Mean & SE & Mean & SE & Mean & SE & Mean & SE \\
\hline $\begin{array}{l}\text { Approximate wave } \\
\text { number (per cm) } \\
\text { Yellow-seed rape }(E\end{array}$ & \multicolumn{4}{|c|}{1650} & \multicolumn{4}{|c|}{1240} & \multicolumn{4}{|c|}{1046} \\
\hline Mean & $39 \cdot 200$ & $2 \cdot 126$ & 0.532 & 0.032 & 1.445 & 0.115 & 0.035 & 0.002 & 36.450 & $1 \cdot 818$ & 0.229 & 0.013 \\
\hline Range & $4 \cdot 14$ & 66.933 & 0.053 & 1.024 & 0.252 & 3.643 & 0.010 & 0.071 & $11 \cdot 330$ & $68 \cdot 277$ & 0.076 & 0.493 \\
\hline \multicolumn{13}{|c|}{ Brown-seed rape (B. napus) } \\
\hline$n$ & \multicolumn{2}{|c|}{36} & \multicolumn{2}{|c|}{36} & \multicolumn{2}{|c|}{36} & \multicolumn{2}{|c|}{36} & \multicolumn{2}{|c|}{36} & \multicolumn{2}{|c|}{36} \\
\hline Mean & $31 \cdot 045$ & 2.591 & 0.440 & 0.039 & 1.329 & 0.141 & 0.032 & 0.003 & $24 \cdot 199$ & $2 \cdot 214$ & 0.161 & 0.015 \\
\hline Range & 8.799 & 54.584 & 0.120 & 0.850 & 0.382 & 2.959 & 0.009 & 0.067 & $9 \cdot 477$ & 44.881 & 0.068 & 0.313 \\
\hline Pooled SEM & \multicolumn{2}{|c|}{2.3699} & \multicolumn{2}{|c|}{0.0353} & \multicolumn{2}{|c|}{0.1286} & \multicolumn{2}{|c|}{0.0025} & \multicolumn{2}{|c|}{2.0257} & \multicolumn{2}{|c|}{0.0140} \\
\hline$P$ value & \multicolumn{2}{|c|}{0.02} & \multicolumn{2}{|c|}{0.07} & \multicolumn{2}{|c|}{0.52} & & & $<0$ & 01 & & \\
\hline
\end{tabular}

tissue. This indicates that the chemical makeup of the microstructure differs between the yellow- $(B$. rapa $)$ and the brown-seeded (B. napus) rape type.

More detailed study is required to define the extent of the differences that exist between the yellow- (B. rapa) and the dark-brown- (B. napus) seeded rape. Such information could be used for the prediction of rapeseed quality and nutritive value for man and animals and for rapeseed breeding programmes for selecting superior varieties of rapeseed for special purposes.

Application 3: use of synchrotron radiation-based Fourier transform infrared microspectroscopy to identify chemical differences in the ultrastructural matrix of endosperm tissue between Harrington (malting-type) and Valier (feed-type) barley in relation to rumen degradation characteristics

Harrington is a malting-type barley variety. As with most barley varieties, its extent and rate of biodegradation in the rumen are high (Yu et al. 2003d). However, if ruminants consume rapidly degradable barley, the incidence of digestive disorders such as bloat and acidosis can increase. This reduces animal performance and can lead to death in acute cases (Nocek \& Tamminga, 1991; Givens et al. 1993). Valier barley has been recently developed as a specialised feed barley for ruminants (Gibson et al. 1994; Bowman et al. 2001). Its extent and rate of rumen degradation are low (Yu et al. 2003d), which should be beneficial to animal performance and health when animals are fed this variety ( $\mathrm{Yu}$ et al. 2003d). Using two dairy models ( $\mathrm{Yu}$ et al. $2003 a$ ), the predicted nutrient supply to dairy cows between Valier and Harrington barley also differed (Yu et al. 2003d). The hypothesis for this study was that the different degradation characteristics between the two barley varieties may be partly due to differences in the starch-protein matrix of the endosperm tissue. As we know, traditional 'wet' chemical analysis cannot detect such biological differences because the inherent seed structures that may inhibit digestion are destroyed during processing for analysis ( $\mathrm{Yu}$ et al.
$2003 d$ ). Chemical analysis also showed that the total chemical composition was similar between the two barleys.

The objective of this study was to use the SR-FTIR technique to identify differences in the structural makeup of Harrington and Valier barley endosperm tissues, so as to obtain a better understanding of the intrinsic structure of barley endosperm tissue in relation to rumen degradation characteristics. The experiment was performed at beamline port 031 in the SRC (University of Wisconsin, Madison).

Photomicrographs of cross-sections of the endosperm tissue of Harrington and Valier barley are presented in Fig. 7. Harrington has larger starch granules that are less densely packed in the protein matrix, relative to Valier. As with traditional analytical methods, it is difficult to pinpoint exact differences. No specific chemical information on barley micro-endosperm tissue is obtained through such images. The results showed that Harrington had a wider range of starch:protein IR absorbance intensity ratio (1.406 to $10.119 v$ v 1.419 to 4.274$)$, suggesting that it is more heterogeneous than Valier in endosperm chemical makeup. Valier had a lower starch:protein IR absorbance intensity ratio than Harrington $(P<0.05 ; 4.121$ (SE 0.576) v. 2.776 (SE 0.270); Fig. 8), which implies that the starch granules in Valier are more closely associated with the protein matrix. This closer association may prevent the starch granules from being rapidly degraded in the rumen.

The lower starch:protein ratio in the micro-endosperm tissue of Valier barley may provide a clue to its reduced effective degradability and the somewhat slower rate of rumen nutrient degradation observed in the in situ study (Yu et al. 2003d). McAllister et al. (1993), for example, suggested that the protein matrix surrounding starch granules is a major factor responsible for differences in the rate of ruminal starch digestion of cereal grains. Efficient starch digestion by ruminal micro-organisms requires an array of fibrolytic, proteolytic and amylolytic enzymes. The extent to which protein and structural $\mathrm{CHO}$ shield underlying starch granules from enzymic attack differs among cereal grains (Wang \& McAllister, 2000). The greater association of the protein matrix with the 


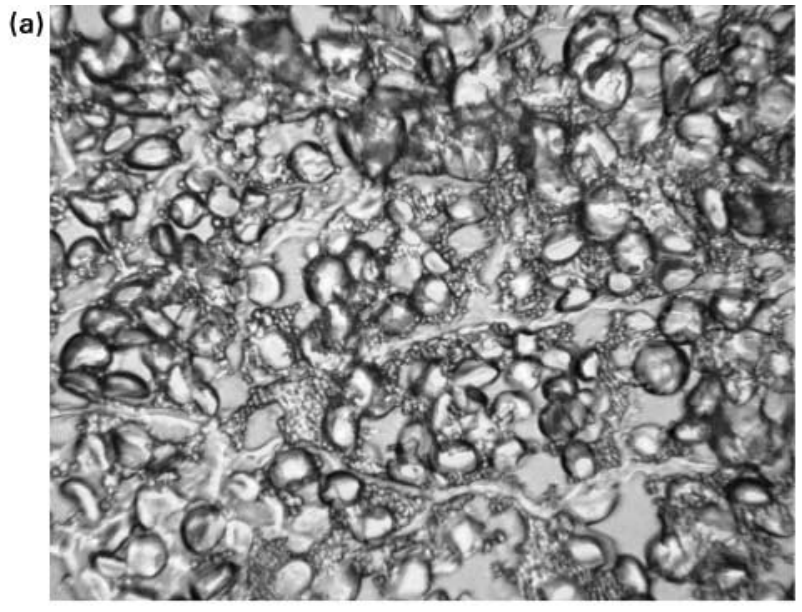

(b)

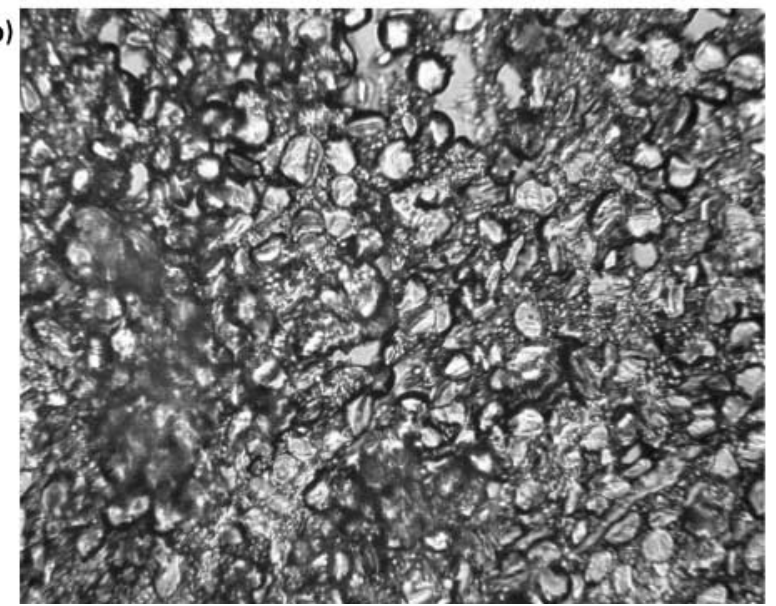

Fig. 7. (a) Photomicrograph of cross-section of the endosperm of Harrington (malting-type) barley. (b) Photomicrograph of cross-section of the endosperm of Valier (feed-type) barley (Olympus $\mathrm{BH}-2$; $10 \times 40$ magnification; photomicrograph width $108.4 \mathrm{~mm} \quad(4.267$ inches) and height $86.7 \mathrm{~mm}$ (3.413 inches)). (From Yu et al. 2004 b.)

starch granules in the endosperm tissue of Valier barley may limit the access of ruminal micro-organisms to the starch granules and thus reduce the rate and extent of degradation relative to that of Harrington barley. This study ( $\mathrm{Yu}$ et al. 2004b) indicated that Harrington and Valier barley differ in their chemical-structural endosperm matrix makeup. The lower starch:protein SR-FTIR absorbance intensity ratio for Valier indicated a tighter association between starch and protein in the endosperm. This may partly explain why Valier exhibits a lower extent and rate of rumen degradation than Harrington barley.

Application 4: using synchrotron radiation-based Fourier transform infrared microspectroscopy to reveal chemical features of feed protein secondary structures and their relation to protein values

Protein secondary structures include $\alpha$-helix and $\beta$-sheet (Fig. 9; Carey, 1996; Mantsch \& Chapman, 1996; Martin, 2002; Dumas, 2003). The relative percentage of the two may influences protein value. A high percentage of $\beta$-sheet may reduce the access of gastrointestinal digestive enzymes to the protein. Reduced accessibility results in poor digestibility and, as a result, low protein value. Feather is

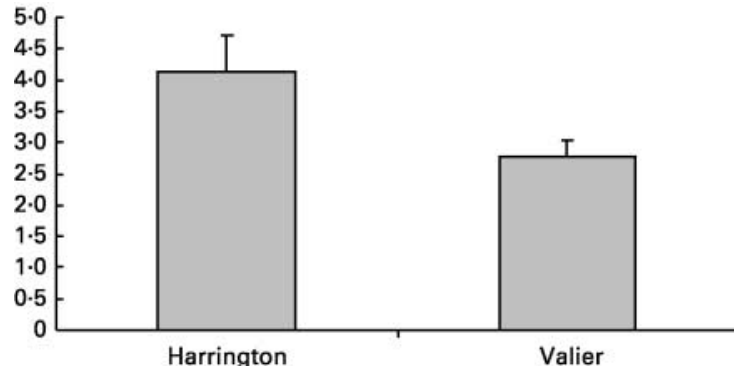

Fig. 8. Starch:protein synchrotron radiation-based Fourier transform infrared absorbance intensity (log $1 / R$ ) ratio in the endosperm tissues of Harrington (malting-type) and Valier (feed-type) barley. Mean values are shown, with their standard errors represented by vertical bars. The mean values are significantly different $(P<0.05)$. (From Yu et al. 2004 b)

widely available as a potential protein supplement in the animal-feed industry. It is high in protein (84\%), but the digestibility is very low (5\%) (Fig. 10). Because of feather's high protein content, it has been of interest in nutritional studies. Other commonly used protein feeds such as barley, oats and wheat have high protein value in terms of digestibility.

The objective of this study (Yu et al. 2004e) was to reveal the chemical features of feather protein secondary structures within amide I at an ultraspatial resolution, in comparison with other commonly used sources of protein; barley (Harrington, 2000-BI-704), oats (CRC Derby) and wheat (Superb-2001). The experiment was carried out on the beamline U2B at the Albert Einstein Center for Synchrotron Biosciences in the NSLS-BNL (US Department of Energy, New York).

The results indicated that ultraspatially resolved imaging of the feed-protein $\beta$-sheet: $\alpha$-helix ratio was possible. Using the SR-FTIR technique, one could distinguish between secondary structures of protein amide I among the different feed-protein sources. The results show that the secondary structure of feather protein differed from other feedprotein sources in terms of the line-shape and position of amide I (Fig. 11). The feather protein amide I band showed a peak at about 1630 per $\mathrm{cm}$ which is consistent with the absorption peak of $\beta$-sheet protein amide I. However, the barley, oat and wheat protein sources showed a peak at about 1650 per $\mathrm{cm}$, which is consistent with the absorption peak of $\alpha$-helix protein amide I. These results indicated that the secondary structure of feather protein contains a higher percentage of $\beta$-sheet. However, barley, wheat and oats contain a lower percentage of $\beta$-sheet but a higher percentage of $\alpha$-helix. With multi-component modelling or a fitting program with Lorentz function, the results showed that feather contains about $88 \% \quad \beta$-sheet and $4 \% \quad \alpha$-helix, barley contains about $17 \% \beta$-sheet and $71 \% \alpha$ - helix; oats contain about $2 \% \beta$-sheet and $92 \% \alpha$-helix; and wheat contains about $42 \% \beta$-sheet and $50 \% \alpha$-helix (Fig. 12). The relative percentage of the two probably explains the differences in biological value of feed proteins. Further study is required to quantify the relationship of percentage of protein secondary structure in relation to protein degradation characteristics and digestibility in animals. Also the effect of processing and treatment on protein structure changes is an area to be investigated. 
(a)

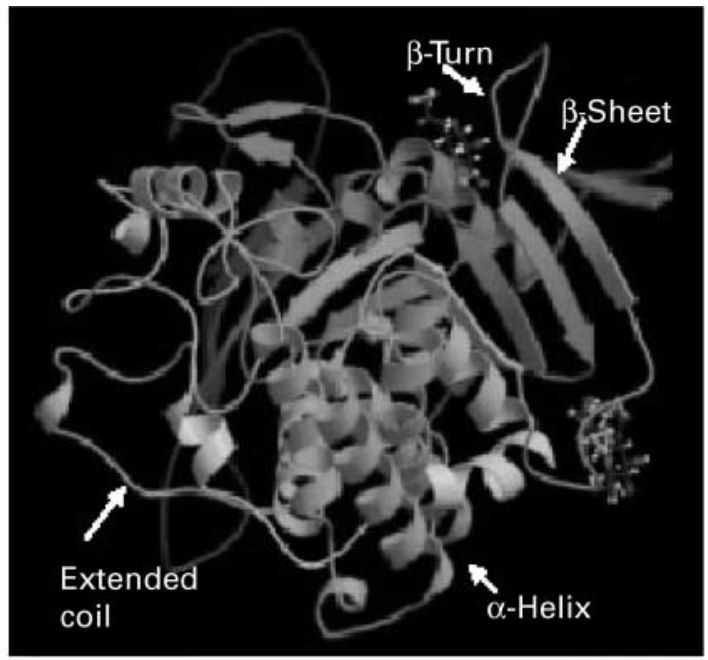

(b)
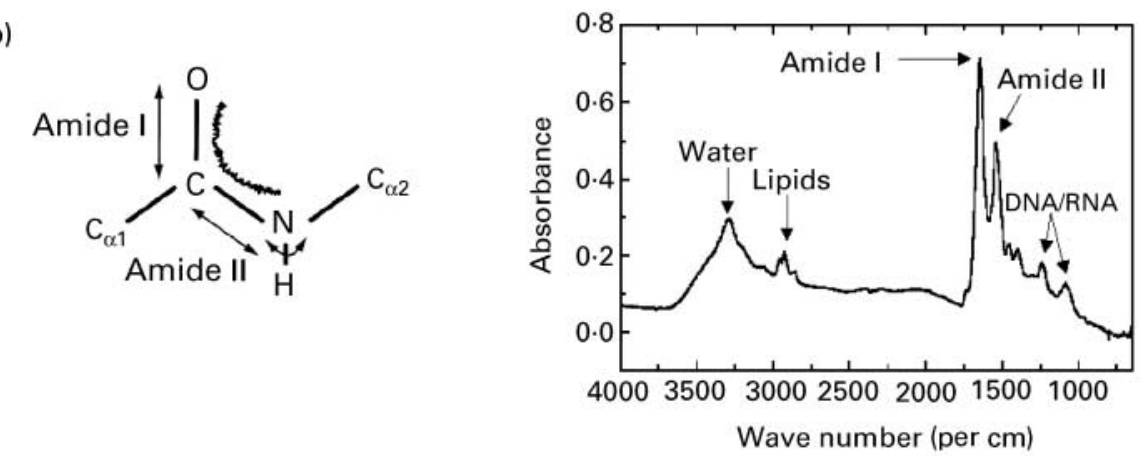
Amide I (band 1600-1700 per $\mathrm{cm}$ ) Amide II (band 1500-1560 per $\mathrm{cm}$ ) $\alpha$-Helix (band $1648-1658$ per $\mathrm{cm}$ )

$\beta$-Sheet (band 1620-1640 per cm)

\author{
Biological system spectra (Amide I and II band in \\ mid IR)
}

Fig. 9. (a) Schematics of protein secondary structure (including $\alpha$-helix and $\beta$-sheet) (from Dumas, 2003). (b) Protein structure determination with sychrotron radiation-based Fourier transform infrared technique. Peak positions of amide I are sensitive to the protein secondary structure $(\alpha$-helix, $\beta$-sheet). For $\alpha$-helix, the peak is at about $1648-1658$ per $\mathrm{cm}$. For $\beta$-sheet, the peak is at about $1620-1640$ per $\mathrm{cm}$ (from Mantsch \& Chapman, 1996; Martin, 2002).

\section{Advantages and disadvantage of synchrotron radiation- based infrared microspectroscopy}

The big advantage of using a synchrotron beam with FTIR spectroscopy to map the tissues is that diffraction limits and spatial resolution are achievable. SR-FTIR microspectroscopic imaging can generate spatially localised chemical information without the need to homogenise the sample as done in traditional analytical chemistry. It combines chemical and spatial information. The chemical information (qualitative and quantitative analytical results) can be linked to structural information.

The main disadvantage is the requirement for a bright synchrotron beam and special instrumentation and the difficulty in sample preparation for some feed materials.

\section{Conclusions and implications}

In conclusion, synchrotron-based IR microspectroscopy can be used as a new tool to reveal ultrastructural-chemical makeup and features within the feed tissue within cellular dimensions, in terms of spectroscopic characteristics, bonding and functional-group characteristics, and biological components ratio characteristics. With the SR-FTIR technique, chemical functional groups can be mapped to indicate chemical composition distribution and intensity

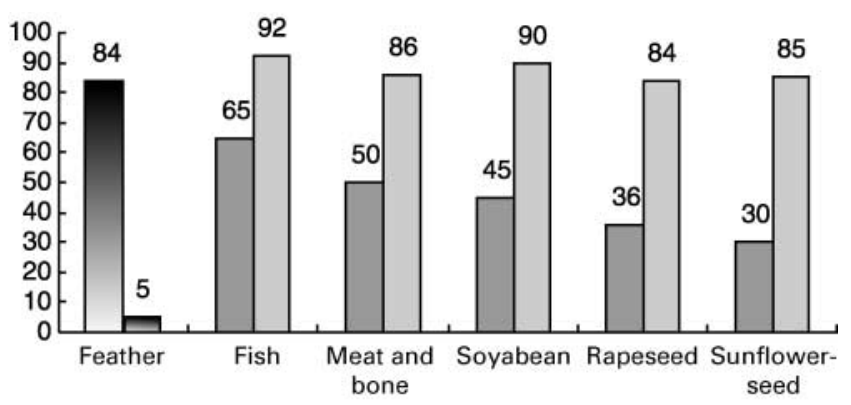

Fig. 10. Protein contents (\%; 1 ) and ruminant total digestibility $(\% ; \square)$ of selected feed-protein sources. 

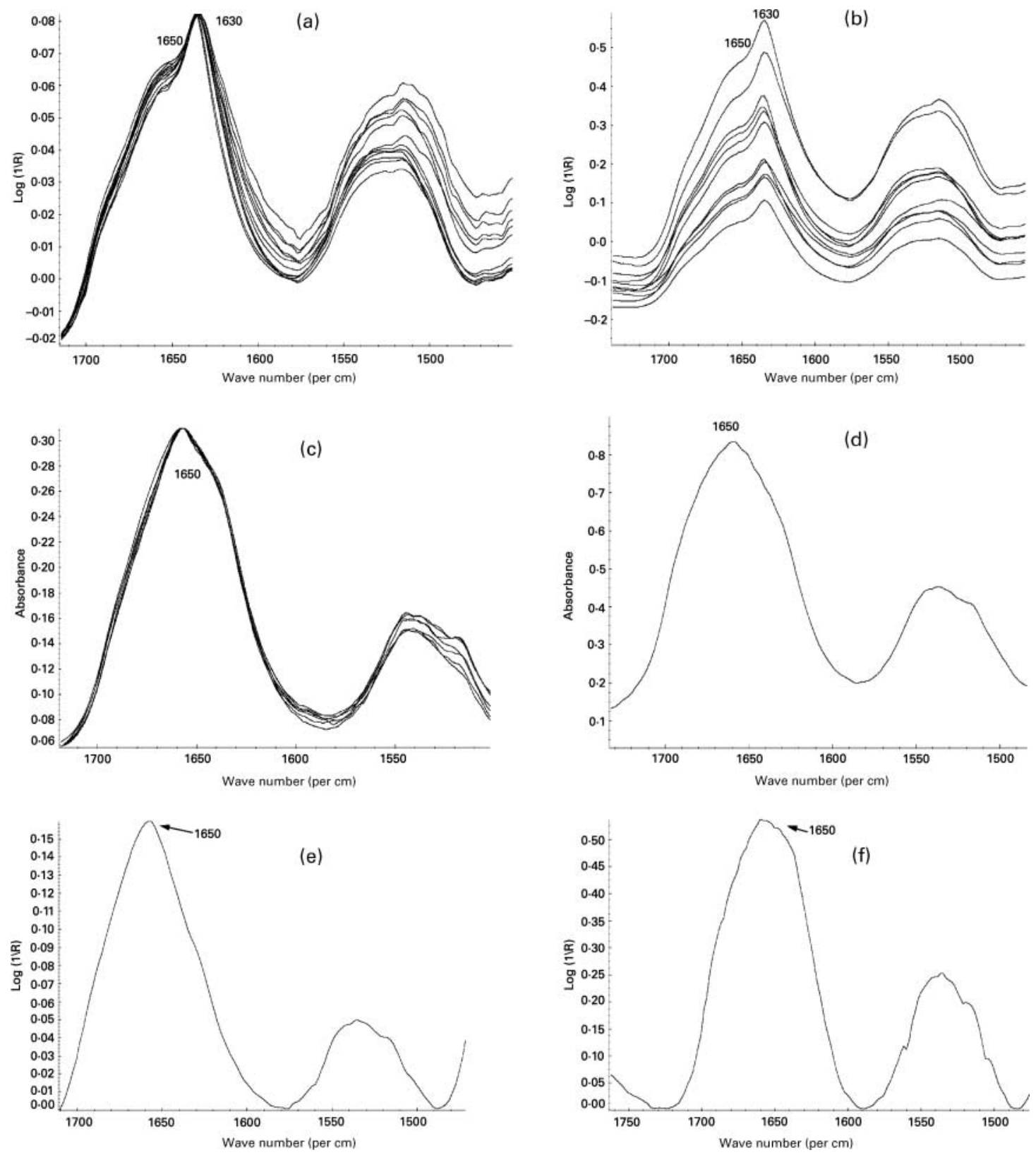

Fig. 11. The line-shape and position of protein amide I from feather protein (a and b); from Harrington barley protein (c and d); from Superb wheat protein (e); from Derby oat protein (f), indicating different protein secondary structures between the two protein sources $(\alpha$-helix at 1650 per $\mathrm{cm}$ and $\beta$-sheet at 1630 per $\mathrm{cm}$ ).

of feed tissues such as lignin, cellulose, protein, lipid and total $\mathrm{CHO}$ and their ratios. These images generate spatially localised chemical information and reveal the chemical information of feed intrinsic structure. The main disadvantage is the requirement for a bright synchrotron light source and special instrumentation and the difficulty in the preparation of some feed samples.

The implications from these studies are that, by using the SR-FTIR technique, we can chemically define the intrinsic structure and analyse individual parts with intact feed

Fig. 12. Multi-component amide I peaks modelling showing feather (a) containing about $88 \% \beta$-sheet and $4 \% \alpha$-helix; barley (b) containing about $17 \% \beta$-sheet and $71 \% \alpha$-helix; oats (c) containing about $2 \% \beta$-sheet and $92 \% \alpha$-helix; wheat (d) containing about $42 \% \beta$-sheet and $50 \% \alpha$-helix. The method of multi-component modelling is performed as follows: step 1, using secondary derivative 'OMNIC', identify amide I component peak frequencies; step 2, using multi-peak fitting program with Lorentz function in 'Origin', quantify the multi-component peaks area in protein amide I region. Lorentz multi-peaks fitting $\chi^{2}$ values for feather, barley, oats and wheat were $0.00018\left(R^{2} 0.98666\right)$, $0.00013\left(R^{2} 0.99755\right), 0.00079\left(R^{2} 0.99581\right)$, and $0.00002\left(R^{2} 0.99744\right)$ respectively. (From Yu et al. 2004 e.) 

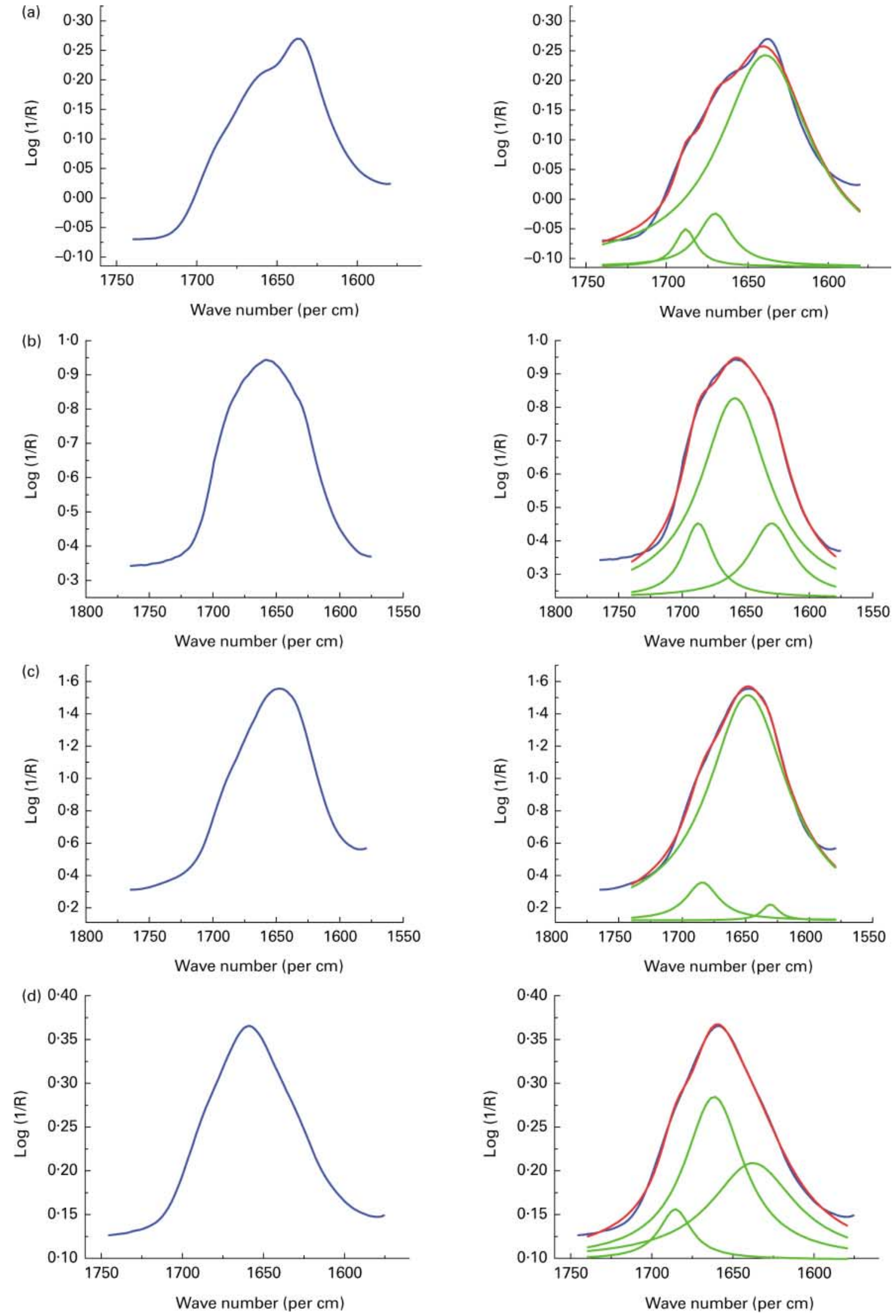
tissues, and we can compare the tissue (species or varieties) according to spectroscopic characteristics, functional groups, spatial distribution or chemical intensity within cellular dimensions. Also, we can relate feed-tissue intrinsic-chemical structures to feed quality, nutrient utilisation and digestive behaviours in animals.

More research is needed on the ultrastructural-chemical makeup of feeds for a better understanding of feed digestive behaviour and nutrient utilisation in animals. The SR-FTIR technique will provide a new opportunity for feed and nutrition research.

\section{Acknowledgements}

The studies are based upon research conducted at the NSLS-BNL (New York, NY, USA) which is supported by the US Department of Energy contract DE-AC0298CH10886 and at the SRC (University of Wisconsin, Madison, WI, USA) which is supported by the NSF under award no. DMR-0084402. We are grateful to Drs Lisa Miller and Nebojsa Marinkovic at U10B and U2B (NSLS-BNL, New York) and Dr Robert Julian at port 031 (SRC, University of Wisconsin, Madison) for their technical assistance in data collection. We would also like to thank Professor Brian Rossnagel (Crop Development Center, University of Saskatchewan) and Director Vern Racz, Professor Philip Thacker and Dr Rex Newkirk (Department of Animal and Poultry Science, University of Saskatchewan) for supplying feed samples. The work was done in cooperation with Professor John Mckinnon, Professor David Christensen (Department of Animal and Poultry Science, University of Saskatchewan) and Scientist Dr Colleen Christensen (Canadian Light Source). This research has been financially supported by the Agricultural Development Fund of Saskatchewan and the Natural Sciences and Engineering Research Council of Canada.

\section{References}

Bonetta DT, Facette M, Raab TK \& Somerville CR (2002) Genetic dissection of plant cell-wall biosynthesis. Biochem Soc Trans 30, 298-301.

Bowman JGP, Blake TK, Surber LMM, Habernicht DK, Daniels TK \& Daniels JT (2001) Genetic factors controlling digestibility of barley for ruminants. In Proceedings of the Western Section, American Society of Animal Science. Accessed June 2001. http://hordeum.oscs.montana.edu/ cowdocs/cow596.htm

Budevska BO (2002) Vibrational Spectroscopy Imaging of Agricultural Products. In Handbook of Vibrational Spectroscopy, vol. 5. Applications of Vibrational Spectroscopy in Life, Pharmaceutical and Natural Sciences, pp. 3720-3732 [JM Chalmers and PR Griffiths, editors]. New York: John Wiley and Sons, Inc.

Carey FA (1996) Organic Chemistry, 3rd ed. New York: McGraw-Hill Companies, Inc.

Cytospec (2004) Software for infrared spectral imaging, version 1.1.01. Croton-on-Hudson, NY: Cytospec Inc.

Dumas P (2003) Synchrotron IR microspectroscopy: A multidisciplinary analytical technique. In The 6th Annual Synchrotron CLS Users' Meeting and Associated Synchrotron Workshops - WinXAS and Infrared. University of Saskatchewan,
Canada, 13-15 November 2003. Saskatoon, SK, Canada: Canadian Light Source Inc. at University of Saskatchewan.

Gibson LA, Bowman JGP, Oberthur LE \& Blake TK (1994) Determination of genetic markers associated with ruminant digestion of barley. Proc West Sect Am Soc Anim Sci 45, 317-320.

Givens DI, Clark P, Jacklin D, Moss AR \& Savery CR (1993) Nutritional aspect of cereal, cereal grain by-products and cereal straw for ruminants. HGCA Research Review, vol. 24. pp. 1-180. London: Home-grown Cereal Authority.

Hergert HL (1971) Infrared Spectra, Lignins: Occurrence, Formation, Structure and Reactions [KV Sarkanen and $\mathrm{CH}$ Ludwig, editors]. New York: Wiley-Interscience.

Himmelsbach DS, Khalili S \& Akin DE (1998) FT-IR microspectroscopic imaging of flax (Linum usitatissimum L.) stems. Cell Mol Biol (Noisy-le-grand) 44, 99-108.

Holman Hoi-Ying N, Bjornstad KA, McNamara MP, Martin MC, McKinney WR \& Blakely EA (2002) Synchrotron infrared spectromicroscopy as a novel bioanalytical microprobe for individual living cells: cytotoxicity considerations. J Biomed Opt 7, 1-10.

Jackson M \& Mantsch HH (1996) Biomedical infrared spectroscopy. In Infrared Spectroscopy of Biomolecules, pp. 311-340 [HH Mantsch and D Chapman, editors]. New York: Wiley-Liss.

Joe LW \& Roth CB (1986) Infrared spectrometry. In Method of Soil Analysis, part 1-Physical and Mineralogical Methods. Agronomy Monograph no. 9, 2nd ed., pp. 291-330 [A Klute, editor]. Madison, WI: American Society of Agronomy and Soil Science Society of America.

Kemp W (1991) Organic Spectroscopy, 3rd ed. New York: W.H. Freeman and Company.

McAllister TA, Phillippe RC, Rode LM \& Cheng KJ (1993) Effect of the protein matrix on the digestion of cereal grains by ruminal microorganisms. J Anim Sci 71, 205-212.

Mantsch HH \& Chapman D (1996) Infrared Spectroscopy of Biomolecules. New York: Wiley-Liss.

Marinkovic NS, Huang R, Bromberg P, et al. (2002) Center for Synchrotron Biosciences' U2B beamline: an international resource for biological infrared spectroscopy. J Synchrotron Rad 9, 189-197.

Marten GC (1989) Current application of NIRS technology in forage research. In NIRS Analysis of Forage Quality. USDA, ARS, Agricultural Handbook no. 643, pp. 45-48. Washington, DC: United States Department of Agriculture.

Martin MC (2002) Fourier-Tranform Infrared Spectroscopy. http://spectroscopy.lbl.gov/FTIR-Martin/

Mathlouthi M \& Koenig JL (1986) Vibrational spectra of carbohydrates. Adv Carbohydr Chem Biochem 44, 7-89.

Miller LM (2002) Infrared microspectroscopy and imaging. http:// nslsweb.nsls.bnl.gov/nsls/pubs/nslspubs/imaging0502/ irxrayworkshopintroduction.htm

Miller LM, Carlson CS, Carr GL \& Chance MR (1998) A method for examining the chemical basis for bone disease: synchrotron infrared microspectroscopy. Cell Mol Biol (Noisy-le-grand) 44, $117-127$.

Miller LM, Carr G, Jackson M, Williams G \& Dumas P (2000) The impact of infrared synchrotron radiation on biology: past, present, and future. Synch Rad News 13, 31-37.

Nocek JE \& Tamminga S (1991) Site of digestion of starch in the gastrointestinal tract of dairy cows and its effect on milk yield and composition. J Dairy Sci 74, 3598-3629.

Norris KH (1988) History, present status, and future prospects for NIRS. In Analytical Application of Spectroscopy, pp. 1-7 [CS Creaser and AMC Davies, editors]. London: Royal Society of Chemistry.

Norris KH (1989) Definition of NIRS analysis. In NIRS Analysis of Forage Quality. USDA, ARS, Agricultural Hand- 
book no. 643, pp. 6 Washington, DC: United States Department of Agriculture.

Norris KH \& Barness RF (1976) Infrared reflectance analysis of nutritive value of feedstuffs. In Feed Composition, Animal Nutrient Requirements and Computerization of Diets, Proceedings of the 1st International Symposium, pp. 237-241 [PV Fonnesbeck, LE Harris and LC Kearl, editors]. Logan, UT: Utah State University.

Raab TK \& Martin MC (2001) Visualizing rhizosphere chemistry of legumes with mid-infrared synchrotron radiation. Planta 213, 881-887.

SAS Institute, Inc. (1998) User's Guide: Statistics, 8th ed. Cary, NC: SAS Institute, Inc.

Simbaya J, Slominski BA, Rakow G, Campbell LD, Downey RK \& Bell JM (1995) Quality characteristics of yellow-seeded Brassica seed meals: protein, carbohydrates and dietary fiber components. J Agric Food Chem 43, 2062-2066.

Slominski BA, Campbell LD \& Guenter W (1994) Carbohydrates and dietary fiber components of yellow and brown-seeded canola. J Agric Food Chem 42, 704-707.

Stewart D, McDougall GJ \& Baty A (1995) Fourier transform infrared microspectroscopy of anatomically different cells of flax (Linum usitatissimum) stems during development. $J$ Agric Food Chem 43, 1853-1858.

Stringam GD, McGregor DI \& Pawlowski SH (1974) Chemical and morphological characteristics associated with seed coat color in rapeseed. In Proceedings of the 4th International Rapeseed Congress, Giessen: Germany, pp. 99-108.

Synchrotron facts (2004) http://www.cls.usask.ca/education/ whatis.php. Accessed October 2004.

Vogel JP, Raab TK, Schiff C \& Somerville SC (2002) PMR6, a pectate lyase-like gene required for powdery mildew susceptibility in Arabidopsis. Plant Cell 14, 2095-2106.

Wang Y \& McAllister TA (2000) Grain processing for ruminants: latest technologies. In Proceedings of the Twenty-First Western Nutrition Conference, Winnipeg, Manitoba, 28-29 September.

Wetzel DL (2001) When molecular causes of wheat quality are known, molecular methods will supersede traditional methods. In Proceedings of the International Wheat Quality Conference II, Manhattan, KS, May 2001, pp. 1-20.

Wetzel DL, Eilert AJ, Pietrzak LN, Miller SS \& Sweat JA (1998) Ultraspatially resolved synchrotron infrared microspectroscopy of plant tissue in situ. Cell Mol Biol (Noisy-le-grand) 44, $145-167$.
Wetzel DL \& LeVine SM (1999) Imaging molecular chemistry with infrared microscopy. Science 285, 1224-1225.

Yu P, Christensen CR, Christensen DA \& McKinnon JJ (2004a) Ultrastructural-chemical makeup of yellow- and brown-seeded Brassica canola within cellular dimensions, explored with synchrotron reflection FTIR microspectroscopy. Can J Plant Sci (In the Press).

$\mathrm{Yu} \mathrm{P}$, Christensen DA, Christensen CR, Drew MD, Rossnagel BG \& McKinnon JJ (2004b) Use of synchrotron Fourier transform infrared microspectroscopy to identify chemical differences in barley endosperm tissue in relation to rumen degradation characteristics. Can J Anim Sci 84 (3), 523-527.

Yu P, Christensen DA \& McKinnon JJ (2003a) Comparison of the National Research Council-2001 model with the Dutch system (DVE/OEB) in the prediction of nutrient supply to dairy cows from forages. J Dairy Sci 86, 2178-2192.

Yu P, McKinnon JJ, Christensen CR \& Christensen DA (2003b) Mapping plant composition with synchrotron infrared microspectroscopy and relation to animal nutrient utilization (invited article and conference speech). In Proceedings of the Canadian Society of Animal Science Annual Conference, Saskatoon, SK, Canada, 10-13 June, pp. 1-20. Saskatchewan, Canada: Canadian Society of Animal Science.

$\mathrm{Yu} \mathrm{P}$, McKinnon JJ, Christensen CR \& Christensen DA (2004c) Using synchrotron transmission FTIR microspectroscopy as a rapid, direct and non-destructive analytical technique to reveal molecular microstructural-chemical features within tissue in grain barley. J Agric Food Chem 52, 1484-1494.

Yu P, McKinnon JJ, Christensen CR \& Christensen DA (2004d) Imaging molecular chemistry of Pioneer corn. J Agric Food Chem (In the Press).

Yu P, McKinnon JJ, Christensen CR \& Christensen DA (2004e) Using synchrotron FTIR microspectroscopy to reveal chemical features of father protein secondary structure, comparison with other feed protein sources. J Agric Food Chem (In the Press).

$\mathrm{Yu}$ P, McKinnon JJ, Christensen CR, Christensen DA, Marinkovic NS \& Miller LM (2003c) Chemical imaging of micro-structures of plant tissues within cellular dimension using synchrotron infrared microspectroscopy. J Agric Food Chem 51, 6062-6067.

Yu P, Meier J, Christensen DA, Rossnagel BG \& McKinnon JJ (2003d) Using the NRC-2001 model and the DVE/OEB system to evaluate nutritive values of Harrington (maltingtype) and Valier (feed-type) barley for ruminants. Anim Feed Sci Technol 107, 45-60. 